\title{
Da experiência francesa em Avaliação Ambiental Estratégica de SAGEs para os Planos de Bacia Hidrográfica do Brasil
}

\author{
From french experience in Strategic Environmental \\ Assessment of SAGEs to Brazilian River Basin \\ Management Plans
}

Simone Mendonça dos Santos ${ }^{1}$ (D), Denise Gallo Pizella² (D), Marcelo Marini Pereira de Souza ${ }^{3}$ (1)

${ }^{1}$ Universidade de São Paulo - USP, São Carlos, SP, Brasil. E-mail: sms@alumni.usp.br

${ }^{2}$ Universidade Estadual Paulista Júlio de Mesquita - UNESP, Ilha Solteira, SP, Brasil. E-mail: denise@bio.feis.unesp.br

3Universidade de São Paulo - USP, Ribeirão Preto, SP, Brasil. E-mail: mps@usp.br

Como citar: Santos, S. M., Pizella, D. G., \& Souza, M. M. P. (2020). Da experiência francesa em Avaliação Ambiental Estratégica de SAGEs para os Planos de Bacia Hidrográfica do Brasil. Revista de Gestão de Água da América Latina, 17, e9. https://doi.org/10.21168/rega.v17e9

\begin{abstract}
RESUMO: Na gestão dos recursos hídricos, o planejamento é o processo que busca definir as melhores alternativas de utilização dos recursos, orientando a tomada de decisão para o alcance de melhores resultados ambientais, sociais e econômicos. Nesse contexto, adquire relevância crescente em função da escassez dos recursos, o papel a ser desempenhado pelos Planos de Bacia Hidrográfica (PBHs) que, por meio de acordos e soluções negociadas entre os diversos atores, identificam alternativas sustentáveis para o aproveitamento dos recursos hídricos na bacia hidrográfica. Por outro lado, é cada vez mais frequente, em âmbito internacional, a utilização da Avaliação Ambiental Estratégica (AAE) como instrumento de apoio à tomada de decisão sustentável no planejamento dos usos dos recursos hídricos. Assim, reconhecendo a França como país de notória experiência em gestão de recursos hídricos, além das similaridades entre os sistema francês e brasileiro de recursos hídricos, o presente artigo partiu da revisão de 12 Relatórios de AAEs de Schémas d'Aménagement et de Gestion des Eaux (SAGE) para a identificação das potenciais contribuições deste instrumento para os PBHs do Brasil. Tendo em vista a promoção de objetivos compartilhados pelos diversos atores sociais, a AAE possibilita a elaboração de PBHs integradores, alinhados ao contexto de planejamento e gestão de recursos hídricos, além de contribuir para a inserção sistemática da perspectiva ambiental nesses Planos. Assim, sugere-se que esforços sejam direcionados para a identificação e validação de procedimentos e técnicas que possibilitem a definição de uma ampla base metodológica para a AAE de PBHs. Ao mesmo tempo, entende-se como necessário o estabelecimento de parcerias junto às Agências de Água, tendo em vista a validação das abordagens metodológicas propostas e a aproximação entre a pesquisa acadêmica e os procedimentos empregados no âmbito dos CBHs.
\end{abstract}

Palavras-chave: Planejamento dos Recursos Hídricos; Plano de Bacia Hidrográfica; Gestão Integrada dos Recursos Hídricos; Articulação Setorial; Participação Pública; Avaliação Ambiental Estratégica.

ABSTRACT: In the management of water resources, planning is the process that seeks to define the best alternatives for the use of resources, guiding decision making in order to achieve better environmental, social and economic results. In this context, the role to be played by River Basin Management Plans (RBMPs) acquires relevance, increasing due to the scarcity of resources, which, through agreements and solutions negotiated between the different actors, identify sustainable alternatives for the development of water resources On the other hand, the use of Strategic Environmental Assessment (SEA) as an instrument to support sustainable decision-making in the planning of water resources is increasingly common at the international level. The use of Strategic Environmental Assessment (SEA) in the elaboration of River Basin Management Plans (RBMPs) is practical in the European Union, both in terms of the Water Framework Directive (WFD) (2000/60 / EC) and SEA Directive (2001/42/EC). Recognizing France as a country of notorious experience in water resources management, the article started by reviewing 12 Schémas d'Aménagement et de Gestion des Eaux (SAGE) SEA reports to identify the potential contributions of this instrument to Brazilian RBMPs. In view of the promotion of regional objectives shared by the various social actors, SEA enables the elaboration of

Recebido: Dezembro 02, 2019. Revisado: Maio 04, 2020. Aceito: Junho 09, 2020. 
integrative RBMPs, aligned with the context of water resources planning and management, and contributes to the systematic insertion of the environmental perspective in these Plans. Thus, it is suggested that efforts should be directed towards the identification and validation of procedures and techniques that enable the definition of a broad methodological basis for the SEA of RBMPs. At the same time, it is understood as necessary to establish partnerships with the Water Agencies for the validation of the proposed methodological approaches and the approximation between academic research and CBHs procedures.

Keywords: Water Resource Planning; River Basin Management Plan; Integrated Management of Water Resources; Sector Articulation; Public Participation; Strategic Environmental Assessment.

\section{INTRODUÇÃO}

A água é um recurso natural com múltiplos usos, essencial à vida humana e aos ecossistemas, características que, em conjunto com a dimensão econômica de algumas dessas utilizações (como a hidroeletricidade, a irrigação, a navegação, o abastecimento e o lazer), constituem fatores de conflito entre seus usuários, demandando um tratamento especial à gestão dos recursos hídricos (Braga et al., 2009). Assim, nas últimas décadas, a busca por um processo de desenvolvimento que envolvesse o uso racional dos recursos hídricos orientou um movimento mundial no sentido da revisão dos quadros legislativos dos diversos países, com a definição de novos instrumentos e arranjos institucionais para a gestão dos recursos hídricos (Liu \& Speed, 2009).

Inspirado no sistema francês de gestão dos recursos hídricos, que devido ao seu pioneirismo na descentralização da tomada de decisão é referência para inúmeros países com regimes de governo e configurações político-administrativas diferentes (Machado, 2003; Lanna et al., 2002; Bohn et al., 2008; Académie de L'eau, 2013), o sistema brasileiro, instituído pela Política Nacional de Recursos Hídricos - PNRH (Lei no. 9.433/1997), definiu a participação pública e a tomada de decisão descentralizada como pilares para a gestão integrada dos recursos hídricos. Ademais, assim como na França, que prevê o planejamento da gestão dos recursos hídricos em diferentes escalas (na escala das grandes bacias hidrográficas, por meio dos Schéma Directeur d'Aménagement et de Gestion des Eaux -SDAGEs e na escala das sub-bacias hidrográficas por meio dos Schéma d'Aménagement et de Gestion des Eaux SAGE), no Brasil, os planos de recursos hídricos devem obedecer a três escalas de planejamento diferentes: nacional, estadual e de bacia hidrográfica (Bohn et al., 2008).

Nesse contexto, adquire relevância o papel a ser desempenhado pelos Planos de Bacia Hidrográfica (PBHs) como instrumentos de planejamento que permitem a construção de consensos entre sociedade civil e agentes econômicos (públicos e privados) na bacia hidrográfica (Porto \& Porto, 2008). Para isso, os PBHs devem considerar tanto as necessidades de longo prazo, quantos as de horizontes mais curtos, incorporando questões ambientais, econômicas e sociais na definição de metas e diretrizes de uso sustentável dos recursos hídricos na bacia ou no conjunto de sub-bacias hidrográficas (Milaré, 2014).

Contudo, elaborar um PBH levando em conta todos os aspectos técnicos e políticos mencionados não é tarefa simples, pressupondo a utilização de mecanismos de identificação de objetivos em comum, de definição de prioridades e de negociação e resolução de conflitos. Ademais, superada a etapa de elaboração, outra grande dificuldade é colocar o PBH elaborado em execução, tornando realidade as ações negociadas (Agência Nacional das Águas, 2013). Portanto, há ainda desafios metodológicos relacionados à consideração dos objetivos e das ações previstas por outros planos setoriais, à articulação entre os atores e instituições envolvidos e ao envolvimento do público ao longo do processo de elaboração dos PBHs (Liefferink et al., 2011; Veiga \& Magrini, 2013; Vicente \& Méndez, 2015; Santos et al., 2020).

Nesse sentido, as abordagens metodológicas integradoras, capazes de identificar o eixo de integração entre os fatores ambientais, sociais, econômicos e institucionais podem desempenhar importante papel, uma vez que: (i) facilitariam a aprovação dos PBHs pelos Comitês de Bacia Hidrográfica (CBHs); (ii) tornariam o PBH elaborado um instrumento norteador das ações na bacia e a base para a elaboração do orçamento do CBH e; (iii) uniriam a sociedade em torno das negociações e pactos firmados, forçando os poderes constituídos (federal, estadual, municipal) e mesmo a iniciativa privada a somente investir nas ações priorizadas no PBH (Zuffo \& Zuffo, 2016).

Por outro lado, em função da necessidade de melhor articular as Políticas, Planos e Programas (PPPs) que apresentem mútua interferência e de inserir a sustentabilidade ambiental em seus objetivos, foi proposto o instrumento de gestão Avaliação Ambiental Estratégica (AAE), atualmente adotado por muitos países (Tetlow \& Hanusch 2012). Com uma abordagem mais ampla que a da 
Avaliação de Impacto Ambiental (AIA) de projetos, a AAE surgiu da necessidade de adoção de abordagens participativas e transparentes, em relação à tomada de decisão, associando crescimento econômico, equidade social e preservação ambiental de modo equilibrado, reforçando o conceito de desenvolvimento sustentável (Espinosa, 1996; Therivel, 2004).

Assim, no ano de 1997, o Conselho da União Europeia (UE) elaborou uma proposta de abordagem para avaliação dos efeitos ambientais de planos e programas de setores estratégicos, que em 2001 foi finalmente aceita e regulamentada no formato da Diretiva 2001/42/CE. Desde então, a Diretiva Europeia sobre AAE, como ficou conhecida, segue influenciando não só os estados membros da UE, mas todo o cenário internacional de Avaliação Ambiental (Therivel, 2004; Fischer, 2007; Dalal-Clayton \& Sadler, 2005; Donnelly et al., 2008). Dessa forma, a aplicação da AAE no processo de concepção de PBHs é praticada na União Europeia, em função da Diretiva Europeia sobre AAE e da Diretiva Quadro da Água - DQA (2000/60/EC) que, ao definir que o processo de elaboração dos PBHs deve considerar as características ambientais da sua área de abrangência, a revisão dos impactos ambientais sobre a qualidade das águas e as influências da legislação vigente no alcance de seus objetivos, fomenta a utilização da AAE (Gullón, 2005; Carter \& Howe, 2006; Vammen, 2008).

Portanto, reconhecendo as similaridades entre os princípios e os instrumentos de planejamento de recursos hídricos do Brasil e da França, bem como o papel que a AAE pode desempenhar na elaboração de PBHs (Arce \& Gullón, 2000; Gullón, 2005; Carter \& Howe, 2006; Larsen \& Kornov, 2009; Vicente \& Méndez, 2015; Agra Filho \& Ramos, 2015), o presente artigo teve como objetivos a revisão da prática francesa de AAE de SAGEs e a identificação das potenciais contribuições desse instrumento para os PBHs do Brasil.

\subsection{Os Sistemas de Planejamento e Gestão de Recursos Hídricos}

\subsubsection{0 sistema Francês}

Em 1964, afastando-se da abordagem tradicional que divide o território em circunscrições administrativas (regiões, departamentos e comunas), a Lei francesa no 64-1.245 (Art. 13) tomou como base o contexto da bacia hidrográfica para gerir os problemas relacionados aos recursos hídricos. Deste modo, foram delimitadas seis grandes bacias hidrográficas (ou grupamentos de bacias hidrográficas): quatro delas organizadas em torno dos cursos d'água de grande extensão: Loire, Rhône, Garonne e Seine, e as outras duas em torno de cursos menores: Rhin e Meuse.

Sobre a Lei de 1964, destaca-se ainda a criação de dois organismos fundamentais para a gestão dos recursos hídricos na escala da bacia hidrográfica: os Comitês de Bacia Hidrográfica (CBHs) e as Agências de Bacia. Com representação paritária da administração central, das coletividades territoriais e dos diferentes setores usuários, aos CBHs foi atribuída a função primordial de arbitrar sobre os conflitos relacionados aos diversos usos da água, enquanto às Agências de Bacia, a responsabilidade pelo suporte técnico necessário ao alcance dos objetivos de desenvolvimento por eles definidos (Martins, 2008). Posteriormente, com a Lei no 92-3 de 1992, o sistema francês de gestão dos recursos hídricos incorporou o território dos departamentos franceses ultramarinos, reconhecendo Guadalupe, Guiana, Martinica, Reunião e Mayotte como regiões hidrográficas (Machado, 2003). Contudo, entre as maiores contribuições da Lei da Água de 1992, destaca-se a instituição de dois novos instrumentos de planejamento e gestão dos recursos hídricos: os SDAGEs e SAGEs. Os SDAGEs são planos estratégicos que estabelecem as orientações fundamentais para a gestão (sustentável) dos recursos hídricos, em um período de 10 a 15 anos. Eles têm caráter obrigatório, sendo elaborados pelas Agências de Água, sob a orientação dos CBHs (Lanna et al., 2002). Os SAGEs definem os objetivos e as regras de utilização dos recursos hídricos no âmbito local, na escala das sub-bacias hidrográficas ou sistema de aquíferos, tendo em vista os objetivos e as diretrizes definidas pelos SDAGEs.

Conforme Lanna et al. (2002), uma nova proposta de SAGE deve vir acompanhada de documentos cartográficos relacionados ao diagnóstico da situação atual, às metas, objetivos e cenários considerados e, às medidas e meios (estruturais, regulamentares e financeiros) para sua implementação. Segundo o artigo $5^{\circ}$ da Lei da Água de 1992, a elaboração, a aplicação e o acompanhamento dos SAGEs são de competência das Comissões Locais de Água - CLA, constituídas por representantes do Estado, das coletividades territoriais e dos usuários dos recursos hídricos (Machado, 2003; Calvo-Mendieta et al., 2017). Importante ressaltar que, a elaboração dos SAGEs é obrigatória apenas para as sub-bacias identificadas como prioritárias no âmbito dos SDAGEs, sendo facultativa nos demais casos. 
Em 2003, iniciou-se na França um processo de revisão da Lei da Água de 1992, cujo objetivo era auxiliar o conjunto de atores e instituições envolvidos no processo de planejamento e gestão dos recursos hídricos no alcance das metas de qualidade definidas pela DQA para a comunidade europeia, criando-se, um quadro único de regulamentação para o desenvolvimento sustentável dos recursos hídricos (Machado, 2003). No ano seguinte, a DQA foi transposta para o direito francês por meio da Lei ${ }^{\circ}$ 2004-338 que, além de sugerir a realização da AAE durante a elaboração dos SAGEs, reforçou o alcance jurídico desses Planos, definindo que as regras estabelecidas no SAGE teriam ampla validade, sobrepondo-se a qualquer decisão contrária em sua área de abrangência (Bohn et al., 2008).

Posteriormente, o referido quadro regulamentar foi ratificado pelos artigos L.122-4 a L.122-11 e pelos artigos R.122-17 a R.122- 24 do Código Ambiental francês (Decreto n²005-613 de 27 de maio de 2005), que definiu como obrigatória a realização da AAE para determinados planos com impactos significativos sobre o meio ambiente, dentre eles aqueles relacionados ao desenvolvimento dos recursos hídricos. Segundo o artigo R.122-20, dentre outros tópicos, os Relatórios de AAE devem apresentar: (i) o resumo dos objetivos, conteúdo e articulação do SAGE com outros planos relacionados; (ii) a fundamentação e justificativa do SAGE em relação aos objetivos ambientais e; (iii) a avaliação dos impactos sobre a Rede Natura $2000^{1}$.

Assim, embora seja facultativa em alguns casos, a elaboração de um SAGE deve sempre ser acompanhada por um processo de AAE. Portanto, como instrumento de apoio à decisão acerca das estratégias de desenvolvimento mais adequadas no recorte das sub-bacias hidrográficas, a AAE de SAGEs é processo previsto pelo sistema francês de gestão de recursos hídricos, cujas etapas sequenciais são descritas no Quadro 1.

Quadro 1. Etapas da Avaliação Ambiental Estratégica dos SAGEs e instrumentos regulatórios

\begin{tabular}{|c|c|}
\hline Etapas da Avaliação Ambiental Estratégica de SAGEs & $\begin{array}{l}\text { Responsável pela } \\
\text { tomada de decisão }\end{array}$ \\
\hline $\begin{array}{l}\text { Cadrage préalable - Escopo da avaliação } \\
\text { (Decreto n }{ }^{\circ} \text { 2012-616 a } 2 \text { de maio de 2012, que regulamenta os artigos R122-17 a } \\
\text { R122-24 do Código Ambiental, relativos às etapas e conteúdo do processo de AAE) } \\
\checkmark \text { Definição do escopo da Avaliação Ambiental Estratégica - nível de detalhamento. }\end{array}$ & $\begin{array}{l}\text { Autoridade } \\
\text { ambiental }\end{array}$ \\
\hline $\begin{array}{l}\text { Avaliação dos potenciais impactos ambientais } \\
\checkmark \text { Diagnóstico do meio } \\
\checkmark \text { Avaliação dos efeitos socioambientais do SAGE sobre o meio } \\
\checkmark \text { Proposição de alternativas de ações do Plano (SAGE) e critérios para sua escolha } \\
\checkmark \text { Medidas corretivas para reduzir, evitar ou compensar impactos socioambientais } \\
\text { negativos de ações presentes no Plano. }\end{array}$ & $\begin{array}{l}\text { Empresa de } \\
\text { consultoria } \\
\text { ambiental } \\
\text { contratada sob a } \\
\text { coordenação da } \\
\text { Comissão Local de } \\
\text { Água }\end{array}$ \\
\hline $\begin{array}{l}\text { Elaboração do Relatório Ambiental da AAE, contendo: (i) um resumo geral dos } \\
\text { objetivos, conteúdo e articulação do SAGE com outros planos relacionados; (ii) uma } \\
\text { descrição do estado atual do ambiente potencialmente afetado e sua provável } \\
\text { evolução na ausência do SAGE e as principais questões ambientais na sua área de } \\
\text { abrangência; (iii) as alternativas selecionadas para o atendimento dos objetivos do } \\
\text { SAGE; (iv) a fundamentação e justificativa do projeto de SAGE em relação aos } \\
\text { objetivos ambientais; (v) a apresentação dos potenciais efeitos significativos sobre o } \\
\text { ambiente e, sempre que possível sobre a saúde humana e a avaliação dos impactos } \\
\text { sobre a Rede Natura 2000; (vi) descrição e apresentação das medidas adotadas para } \\
\text { mitigar os impactos negativos e amplificar os positivos; (vii) apresentação dos } \\
\text { métodos utilizados e; (viii) um relatório não técnico. } \\
\text { (artigo R 122-20 do Código Ambiental, relativo ao conteúdo do relatório ambiental) }\end{array}$ & $\begin{array}{c}\text { Empresa de } \\
\text { consultoria } \\
\text { ambiental } \\
\text { contratada, } \\
\text { condicionada à } \\
\text { aprovação da } \\
\text { Comissão Local de } \\
\text { Água }\end{array}$ \\
\hline $\begin{array}{l}\text { Parecer acerca da Avaliação e do Relatório Ambiental da AAE- a entidade pública } \\
\text { responsável pela elaboração ou adoção do plano deverá submeter à apreciação da } \\
\text { autoridade ambiental o arquivo que contém a versão preliminar do plano, diagramas, } \\
\text { programas ou outros documentos associados, o relatório de impacto ambiental e os } \\
\text { documentos e avisos exigidos pelas leis e regulamentos aplicáveis que foram }\end{array}$ & $\begin{array}{l}\text { Autoridade } \\
\text { Ambiental }\end{array}$ \\
\hline
\end{tabular}

1 A Rede Natura 2000 constitui conjunto de áreas prioritárias para a conservação da biodiversidade, estabelecidas com base nas Diretivas Aves e Habitats (Diretivas 79/409/CEE e 92/43/CEE, respectivamente), que constitui uma importante ferramenta de ordenamento do espaço natural e econômico da União Europeia. Na França, a Rede Natura 2000 inclui 1.753 sítios. 0 decreto no 2012 365 a 9 de abril de 2010 introduz a obrigatoriedade de se realizar um estudo sobre os impactos dos SAGEs e de outros documentos de planejamento sobre a Rede Natura 2000. A avaliação desses impactos segue as diretrizes do artigo R. 414-22 do Código Ambiental francês. 
Quadro 1. Continuação...

\begin{tabular}{|c|c|}
\hline Etapas da Avaliação Ambiental Estratégica de SAGEs & $\begin{array}{l}\text { Responsável pela } \\
\text { tomada de decisão }\end{array}$ \\
\hline \multicolumn{2}{|l|}{$\begin{array}{l}\text { prestados na data da referência. Na ocasião, a Autoridade Ambiental é também } \\
\text { consultada acerca do prazo e das melhores condições para o processo de consulta } \\
\text { pública. } \\
\text { (artigo R.122-21 do Código Ambiental, relativo à necessidade de parecer da } \\
\text { autoridade do Estado responsável pelo meio ambiente) }\end{array}$} \\
\hline $\begin{array}{l}\text { Consulta ao público - as coletividades territoriais e outros grupos de interesse têm } \\
\text { acesso à versão preliminar dos Planos e dos documentos relacionados, podendo se } \\
\text { manifestar dentro de prazo definido pela autoridade ambiental. Após recolhimento e } \\
\text { ponderação das críticas e sugestões do público, a versão final do Plano é elaborada } \\
\text { pela Comissão Local de Água. } \\
\text { (artigos R122-22 a R122-23 do Código Ambiental, relativos à necessidade de } \\
\text { informação e participação pública) }\end{array}$ & $\begin{array}{l}\text { Comissão Local de } \\
\text { Água }\end{array}$ \\
\hline $\begin{array}{l}\text { Aprovação do SAGE - a versão final do Plano é submetida à aprovação do Chefe de } \\
\text { Departamento para verificação da pertinência e compatibilidade com os instrumentos } \\
\text { regulatórios relacionados. }\end{array}$ & $\begin{array}{c}\text { Chefe de } \\
\text { Departamento }\end{array}$ \\
\hline $\begin{array}{l}\text { Declaração - resumo acerca da ponderação dos resultados do Relatório e das } \\
\text { consultas públicas no SAGE, contendo as razões que fundamentaram as escolhas } \\
\text { realizadas e as medidas relativas ao monitoramento dos efeitos do SAGE sobre o } \\
\text { ambiente. } \\
\text { (artigo L.122-10 do Código Ambiental) }\end{array}$ & $\begin{array}{c}\text { Comissão Local de } \\
\text { Água }\end{array}$ \\
\hline $\begin{array}{l}\text { Informação do público (Plano de comunicação) - definição de mecanismos de } \\
\text { divulgação e acompanhamento por parte do público das etapas de implementação do } \\
\text { Plano (documentos digitais e sítios na internet podem ser utilizados) }\end{array}$ & $\begin{array}{l}\text { Comissão Local de } \\
\text { Água }\end{array}$ \\
\hline $\begin{array}{l}\text { Monitoramento - um quadro de monitoramento (tableau de bord) contendo um atlas } \\
\text { cartográfico, com cartas temáticas de indicadores ambientais baseados no modelo } \\
\text { conceitual Pressão - Estado - Resposta (OECD, 1993), além de breve descrição dos } \\
\text { métodos de monitoramento adotados é utilizado pela Comissão Local de Água como } \\
\text { meio de acompanhamento dos resultados obtidos com o Plano. }\end{array}$ & $\begin{array}{c}\text { Comissão Local de } \\
\text { Água }\end{array}$ \\
\hline
\end{tabular}

\subsubsection{Sistema brasileiro}

O Brasil apresenta grandes variações temporais e espaciais na distribuição hídrica, as quais, em conjunto com as desigualdades regionais de desenvolvimento econômico e os diferentes graus de ocupação das atividades produtivas, fazem com que o País apresente amplo espectro de condições e problemas ambientais (Braga et al., 2009), de modo que o planejamento adequado das ações relacionadas aos recursos hídricos segundo princípios de sustentabilidade social, econômica e ambiental é fundamental (Tucci, 2006).

Assim, seguindo uma tendência internacional em termos de gestão descentralizada no âmbito da bacia hidrográfica, a Política Nacional de Recursos Hídricos - PNRH (Lei nº 9.433 de 1997) (Brasil, 1997) buscou a instituição de um conjunto de instrumentos de planejamento e gestão capazes de subsidiar: o estabelecimento de objetivos e metas de desenvolvimento sustentável no âmbito das bacias hidrográficas, o disciplinamento dos usos dos recursos hídricos, o incentivo ao uso racional dos recursos hídricos e a estruturação de uma base de dados e informações acessíveis ao público (Porto \& Porto, 2008). Dessa forma, no artigo $5^{\circ}$ da PNRH, foram definidos os seguintes instrumentos: os planos de recursos hídricos, o enquadramento dos corpos d'água segundo seus usos preponderantes, a outorga de direito de uso dos recursos hídricos, a cobrança pelo uso dos recursos hídricos, a compensação a Municípios (que não foi regulamentado) e o Sistema de Informações sobre Recursos Hídricos.

Dentre os planos de recursos hídricos, encontram-se os Planos de Bacias Hidrográficas (PBHs), instrumentos de planejamento que constituem oportunidade para o estabelecimento de soluções negociadas entre os diversos atores sociais, cujo processo de elaboração tem seu escopo definido em uma etapa preparatória que compreende os seguintes procedimentos (Resolução do CNRH no. 145 de 2012) (Brasil, 2012):

(i) A definição do Termo de Referência (TR) contendo as definições, diretrizes e temas relevantes, além dos produtos que se espera obter com o plano. Importante ressaltar que o TR decorre da construção coletiva entre os atores intervenientes na gestão dos recursos hídricos no território da bacia hidrográfica, sendo debatido e aprovado no âmbito do comitê de bacia, com apoio das 
agências de água (ou entidades delegatárias de suas funções) e da respectiva entidade gestora de recursos hídricos;

(ii) 0 estabelecimento de um arranjo institucional para acompanhar a execução dos trabalhos a serem desenvolvidos pela equipe técnica do órgão gestor ou por equipe contratada para a elaboração do plano. Este arranjo define os participantes envolvidos no processo, os papéis a serem assumidos e a dinâmica de comunicação entre as partes.

De acordo com a ANA (Agência Nacional das Águas, 2013), que estabelece as diretrizes para a elaboração dos PBHs, o processo de elaboração dos PBHs, após a referida etapa preparatória são esperados os seguintes procedimentos:

- Diagnóstico da situação atual dos recursos hídricos: orientado aos problemas da bacia, de forma a explicitar as relações de interdependência entre o meio físico e as atividades socioeconômicas;

- Prognóstico: contemplando um cenário tendencial, uma prospecção de cenários alternativos e as medidas propostas para gestão e uso sustentável dos recursos hídricos (cenário normativo) na bacia hidrográfica;

- Plano de ações: estruturado por meio de um conjunto metas, diretrizes e medidas de intervenção, tendo em vista a mitigação, minimização e antecipação dos problemas relacionados aos recursos hídricos, compatibilizando-se os recursos financeiros com as ações previstas;

- Monitoramento e Revisão: acompanhamento da implementação e revisão do Plano, de forma a subsidiar a elaboração de Relatórios de acompanhamento.

Por fim, com o objetivo de coordenar a gestão integrada dos recursos hídricos, a PNRH criou o Sistema Nacional de Gerenciamento de Recursos Hídricos, que atua por meio da ação coordenada dos seguintes órgãos/entidades (Porto \& Porto, 2008):

- Conselho Nacional de Recursos Hídricos (CNRH) - constituído por representantes dos Ministérios, dos Conselhos Estaduais, dos usuários e das organizações civis, encarregado de elaborar o Plano Nacional, articular os diversos níveis de planejamento e arbitrar conflitos entre os Conselhos Estaduais de Recursos Hídricos;

- $\quad$ Agência Nacional de Águas - criada pela Lei 9.984/2000, atua na regulação do acesso e uso dos recursos hídricos de domínio da União, definindo e fiscalizando o cumprimento de normas; no acompanhamento da situação dos recursos hídricos em âmbito nacional e; no apoio e na coordenação dos órgãos gestores estaduais, dos Comitês e Agências de Bacia;

- Comitês de Bacias Hidrográficas (CBHs) - órgãos consultivos e deliberativos com jurisdição sobre bacias, sub-bacias ou grupos de bacias contíguas, constituídos por representantes da União, dos Estados, dos municípios, com atribuição de arbitrar conflitos entre usuários, arbitrar rateio de custos de obras de uso múltiplo, aprovar os Planos de Bacia Hidrográfica (PBHs) e os valores a serem cobrados dos usuários pelo uso dos recursos hídricos;

- Agências da Água - Secretarias Executivas que podem atender a um Comitê ou grupo de Comitês, com as atribuições de elaborar os PBHs, gerir o Sistema de Informações em sua jurisdição, contrair e conceder empréstimos, efetuar cobranças e propor ao respectivo Comitê o enquadramento dos corpos d'água, os valores das cobranças pelo uso, bem como o plano de aplicação dos recursos financeiros e o rateio das obras.

Para Lanna et al. (2002), Porto \& Porto (2008) e Santos et al. (2020), os procedimentos metodológicos de elaboração de PBHs devem promover as efetivas articulações verticais (entre o PBH elaborado e os Planos Estaduais e Nacional de recursos hídricos) e horizontais (entre o PBH elaborado e outras estratégias setoriais correlacionadas com a gestão hídrica, tais como os planejamentos regionais e municipais de uso e ocupação do solo). Contudo, apesar da importância estratégica atribuída aos PBHs, entraves técnicos e políticos têm dificultado a definição de PBHs capazes de integrar as demandas, os objetivos e os valores dos diversos atores envolvidos no processo decisório no âmbito dos CBHs, limitando a implementação e adoção desses Planos por parte dos diversos setores usuários (Campos \& Sousa, 2003).

\section{METODOLOGIA}

\subsection{Pesquisa e seleção documental}

Atualmente a França conta com 12 comitês de bacia hidrográfica - CBH: 7 na região metropolitana (Adour Garonne, Artois Picardie, Loire Bretagne, Rhin Meuse, Rhône Méditerranée, Seine Normandie e Corse) e 5 nos departamentos franceses ultramarinos (Guadeloupe, Martinique, Guyane, Réunion e Mayotte) (Le Service Public D'information sur L'eau, 2014). Dessa forma, buscando-se identificar a 
quantidade de SAGEs disponíveis para consulta em meio eletrônico, foram realizadas consultas ao banco de dados do Sistema francês de Informações sobre a Água ${ }^{2}$, que reúne os sites ${ }^{3}$ e as informações as informações prestadas pelas instituições que integram o sistema francês de gestão de recursos hídricos. Portanto, em consulta realizada em julho de 2014, foram identificados 180 SAGEs em diferentes estágios de desenvolvimento e implementação, distribuídos conforme Tabela 1.

Tabela 1. Quantidade de SAGEs disponíveis em meio eletrônico em julho de 2014

\begin{tabular}{c|c}
\hline Estágio & Quantidade \\
\hline Não iniciado & 1 \\
\hline Emergência & 3 \\
\hline Instrução & 2 \\
\hline Elaboração & 87 \\
\hline Implementação & 58 \\
\hline Primeira revisão & 27 \\
\hline Total & $\mathbf{1 8 0}$
\end{tabular}

Nota: Não iniciado: SAGEs para os quais já foi autorizada a delimitação da área de abrangência, porém o Comitê de bacia ainda não se pronunciou; Emergência: SAGEs para os quais o Comitê de bacia já se pronunciou acerca da área de abrangência; Instrução: SAGEs para os quais, após a delimitação da área de abrangência, iniciou-se o processo de organização e instalação da CLE; Elaboração: SAGEs em processo de elaboração pelas CLEs; Implementação: SAGEs já aprovados por portaria; Primeira Revisão: SAGEs aprovados antes Lei $n$ o 2006-1772 (LEMA) e que, portanto, devem entrar em conformidade com as novas disposições legais.

Fonte: Eaufrance (Le Service Public D'information sur L'eau, 2014)

Considerando-se que apenas os SAGEs implementados possuem Relatórios de AAE aprovados, para análise e revisão documental, a partir dos 58 Relatórios de AAEs de SAGEs implementados e disponíveis, buscou-se a estruturação de um conjunto amostral que contivesse ao menos dois Relatórios de cada um dos 12 CBHs franceses. Contudo, até julho de 2014, nem todos os comitês tinham uma quantidade suficiente de SAGEs implementados para esse fim. Portanto, ao final dos procedimentos de busca, foi estruturado um conjunto amostral contendo 12 Relatórios de AAEs de SAGEs (Tabela 2).

Tabela 2. Relatórios AAEs de SAGEs selecionados para revisão, contendo os Comitês de Bacia dos quais fazem parte, a sub-bacia de referência, o ano de publicação e a versão.

\begin{tabular}{|c|c|c|c|}
\hline Comitê de Bacia & Sub-bacia & Ano & Versão \\
\hline \multirow{2}{*}{ Adour-Garonne } & 1. Celé & 2011 & $1 \mathrm{a}$ \\
\hline & 2. Estuaire de la Gironde et Milieux associés & 2010 & $1 \mathrm{a}$ \\
\hline \multirow{2}{*}{ Artois-Picardie } & 3. Canche & 2011 & $1 \mathrm{a}$ \\
\hline & 4. Delta de I'Aa & 2010 & $1 \mathrm{a}$ \\
\hline Corse & 5. Etang de Biguglia & 2012 & $1 \mathrm{a}$ \\
\hline \multirow{2}{*}{ Loire-Bretagne } & 6. Baie Saint-Brieuc & 2013 & $1 \mathrm{a}$ \\
\hline & 7. Sioule & 2012 & $1 \mathrm{a}$ \\
\hline Rhin-Meuse & 8. Ill Nappe Rhin & 2013 & $2 \mathrm{a}$ \\
\hline \multirow{2}{*}{ Rhône-Mediterranée } & 9. Bassin Ferrifère & 2015 & $1 \mathrm{a}$ \\
\hline & 10. Drôme & 2013 & $2 \mathrm{a}$ \\
\hline \multirow{2}{*}{ Seine-Normandie } & 11. Aisne Vesle Suippe & 2013 & $1 \mathrm{a}$ \\
\hline & 12. Cailly, Aubette, Robec & 2014 & $2 a$ \\
\hline
\end{tabular}

Fonte: elaborada pelos autores (2020)

\subsection{Avaliação dos Relatórios de AAEs de SAGEss}

O processo de avaliação dos Relatórios selecionados contemplou as seguintes etapas:

1. Inicialmente, para a revisão dos Relatórios selecionados utilizou-se de uma lista de critérios que buscou refletir os requisitos da Diretiva Europeia sobre AAE. A referida lista foi estruturada a partir da adaptação de lista elaborada por Fischer $(2007,2010)$ para estudos de revisão da qualidade de Relatórios de AAEs de planos de ordenamento territorial na Inglaterra - para exemplos de aplicação em outros setores, ver Lemos et al. (2012); Phylip-Jones \& Fischer (2015).

20 Sistema francês de Informações sobre a Água é um dispositivo criado pelo Estado para compartilhar e tornar públicos os dados disponíveis sobre a água. 0 sistema foi introduzido no Código Ambiental francês (artigo L213-2) pela Lei sobre água e ambientes aquáticos, de 30 de dezembro de 2006.

${ }^{3}$ As buscas concentraram-se no site do Serviço Público de Informações sobre a água - Eaufrance (http://www.eaufrance.fr/), no banco de dados e ferramentas para a gestão integrada da água - Gest'eau (http://www.gesteau.eaufrance.fr/) e, quando existente, nos sites desenvolvidos por iniciativa das Comissões Locais de Água para a divulgação do SAGE. 
Ressalta-se que o conjunto de critérios abordados na referida lista está alinhado às boas práticas em AAE preconizadas na literatura internacional (Fischer \& Gazzola, 2006). Assim, visando à adaptação da lista de Fischer $(2007,2010)$ ao contexto francês de planejamento e gestão dos recursos hídricos, do conjunto inicial de 43 critérios propostos, foram retirados aqueles relacionados ao quadro normativo inglês e adicionados outros, relativos às diretrizes francesas de AAE de SAGEs (France, 2012), obtendo-se uma lista de 37 critérios de revisão da qualidade (Quadro 2). Assim, após a leitura integral dos Relatórios, o atendimento aos 37 critérios foi avaliado qualitativamente, caso a caso, segundo escala apresentada na Tabela 3. Destaca-se que para a realização da referida avaliação empregou-se o método de dupla-checagem, de forma que, todos os Relatórios de AAE foram revisados por dois dos autores deste artigo, com posterior comparação e discussão dos resultados até a obtenção de consenso.

Quadro 2. Critérios para revisão da qualidade dos Relatórios de AAEs de SAGEs

\begin{tabular}{|c|}
\hline $\begin{array}{l}\text { SEÇÃo } 1 \text { - Linha de base ambiental e Integração com a elaboração do SAGE } \\
\text { O Relatório Ambiental: }\end{array}$ \\
\hline 1. Informa o conteúdo e os principais objetivos do SAGE? \\
\hline 2. Informa a relação do SAGE com outros planos e programas relevantes? \\
\hline 3. Descreve como a AAE foi realizada? \\
\hline $\begin{array}{l}\text { 4. Descreve como a AAE e o processo de elaboração do SAGE se integram (verificar se a Avaliação Ambiental } \\
\text { foi realizada durante a elaboração do SAGE e antes de sua adoção)? }\end{array}$ \\
\hline $\begin{array}{l}\text { 5. Descreve quais questões foram abordadas por outros estudos/avaliações (noutros níveis na hierarquia de } \\
\text { planejamento)? }\end{array}$ \\
\hline $\begin{array}{l}\text { 6. Fornece informações sobre aspectos relevantes do estado atual do ambiente, sobre aspectos sociais e } \\
\text { econômicos significativos, bem como a evolução desses na ausência do SAGE, indicando as lacunas existentes } \\
\text { na base de dados? }\end{array}$ \\
\hline $\begin{array}{l}\text { 7. Fornece informações sobre os problemas ambientais existentes, de interesse para o SAGE, incluindo } \\
\text { aqueles relacionados às áreas de relevante interesse ambiental? }\end{array}$ \\
\hline $\begin{array}{l}\text { 8. Fornece informações sobre objetivos e estratégias de proteção ambiental, adotados internacionalmente, na } \\
\text { Europa ou na França, e de que forma esses objetivos foram ponderados na elaboração do SAGE? }\end{array}$ \\
\hline SEÇÃO 2 - Avaliação e questões-chave \\
\hline $\begin{array}{l}\text { O Relatório Ambiental: } \\
\text { 9. Descreve como as alternativas foram identificadas, considerando-se os objetivos e escopo geográfico do } \\
\text { SAGE? }\end{array}$ \\
\hline 10. Lista as questões ambientais/de sustentabilidade consideradas na avaliação? \\
\hline 11. Descreve como essas questões ambientais/de sustentabilidade foram identificadas e priorizadas? \\
\hline $\begin{array}{l}\text { 12. Fornece informações sobre prováveis efeitos significativos das diferentes opções sobre os seguintes } \\
\text { temas (quando o tema não for abordado, verificar se o relatório informa os motivos para sua exclusão): } \\
\text { Zonas úmidas e ambientes naturais (Biodiversidade); Poluição da água e qualidade; Recursos hídricos e } \\
\text { quantidade; Riscos, inundações; Paisagem; Saúde humana; Solo; Ar; Mudanças climáticas; Energia e balanço } \\
\text { energético; Fauna; Flora; Bens materiais; Herança cultural, incluindo arquitetura e arqueologia e; a inter- } \\
\text { relação entre os fatores anteriormente citados? }\end{array}$ \\
\hline 13. Confronta os objetivos do SAGE com os objetivos da AAE? \\
\hline $\begin{array}{l}\text { 14. Estabelece que assuntos são mais apropriadamente avaliados em outros níveis da hierarquia de } \\
\text { planejamento, a fim de evitar a duplicação de avaliação? }\end{array}$ \\
\hline 15. Mostra como o "estado da arte" do conhecimento e os métodos de avaliação foram utilizados? \\
\hline SEÇÃO 3 - Determinação da significância dos impactos \\
\hline $\begin{array}{l}\text { A significância dos impactos é apresentada em função: } \\
\text { 16. Do grau em que o SAGE estabelece uma estrutura para níveis subsequentes da hierarquia de } \\
\text { planejamento (programas e projetos), em termos de localização, dimensões, condições, ou alocação de } \\
\text { recursos? }\end{array}$ \\
\hline $\begin{array}{l}\text { 17. Do valor e a vulnerabilidade da área provavelmente afetada pelas opções/alternativas devido às } \\
\text { características naturais relevantes ou, dependendo do caso, os limites/padrões de qualidade ambiental que } \\
\text { serão excedidos foram identificados? }\end{array}$ \\
\hline
\end{tabular}


Quadro 2. Continuação...

18. Dos efeitos de cada opção/alternativa sobre áreas ou paisagens reconhecidas/protegidas nacional ou internacionalmente foram identificados?

19. Da probabilidade, a duração (de curto, médio ou longo prazo, permanente ou temporário), a frequência e a reversibilidade dos efeitos, negativos e positivos, das opções/alternativas foram identificadas?

20. Dos efeitos secundários, cumulativos e sinérgicos das opções/alternativas foram identificados?

21. Da natureza transfronteiriça dos efeitos de cada opção/alternativa foi identificada?

22. Dos riscos à saúde humana e a questões ambientais/de sustentabilidade que decorrem implementação das opções/alternativas do SAGE foram identificados?

23. Da magnitude e a extensão espacial dos efeitos (área geográfica e o tamanho da população afetada) das opções/alternativas foram identificadas?

\section{SEÇÃO 4 - Processo de consulta}

O Relatório Ambiental:

24. Descreve como as autoridades foram consultadas na ocasião da definição do escopo da avaliação e do nível de detalhe da informação a ser avaliada?

25. Descreve como o projeto do SAGE e o Relatório Ambiental foram disponibilizados às autoridades ou ao público provavelmente afetado pelo SAGE e, se tiveram a oportunidade de expressar suas opiniões em tempo hábil para que as suas considerações fossem ponderadas no plano?

26. Confirma se os resultados das consultas sobre o plano ou a avaliação foram considerados na tomada de decisão?

27. Confirma se, no caso de mudanças significativas decorrentes da participação pública, uma nova AAE será realizada?

\section{SEÇÃO 5 - Apresentação e informação dos resultados}

O Relatório Ambiental:

28. Utiliza termos concisos, descrições gráficas e literais, dados confiáveis, com claros pontos de vista, argumentos suficientes, para a descrição das principais decisões tomadas?

29. Inclui uma seção claramente distinguível para a avaliação ambiental do SAGE ou um Relatório Ambiental em separado, preparado de acordo com os requisitos da Diretiva Europeia sobre AAE?

30. Fornece informações sobre quaisquer dificuldades (deficiências técnicas ou lacunas de know-how) ou incertezas encontradas?

31. Uma vez definida a versão final do SAGE, esta é acompanhada de informações sumarizadas de como as considerações de sustentabilidade foram integradas, de como os resultados das consultas foram ponderados e quais as razões para a escolha da versão final adotada (justificar as escolhas em termos de objetivos de proteção ambiental)?

\section{SEÇ̃̃O 6- Recomendações sobre as alternativas preferenciais e monitoramento}

O Relatório Ambiental:

32. Apresenta as razões para a seleção das opções/alternativas em análise, bem como a descrição de como a avaliação levou a tal seleção?

33. Fornece informações sobre as medidas previstas para se evitar, reduzir e, sempre que possível, eliminar quaisquer efeitos adversos significativos sobre os componentes ambientais?

34. Descreve as medidas previstas para o monitoramento dos efeitos ambientais significativos, a fim de se identificar os efeitos indesejáveis?

35. Descreve como efeitos positivos podem ser maximizados?

36. Informa os responsáveis pelo monitoramento e, nesse contexto, explicita os métodos (tempo, frequência e acurácia das medições), os critérios de análise e os indicadores - incluindo prazos - a serem empregados no processo de monitoramento?

37. Explica se os sistemas de controle/monitoramento existentes devem ser utilizados e como utilizá-los, a fim de se evitar duplicidade de ações?

Fonte: Adaptado de Fischer (2010)

Nota: as linhas em destaque identificam os critérios de maior relevância nas seções 
Tabela 3. Escala de avaliação dos Relatórios de AAEs quanto ao atendimento aos critérios de revisão da qualidade.

\begin{tabular}{|c|c|}
\hline Nível de atendimento & Descrição \\
\hline CATEGORIA - A & Trabalho bem realizado sem omissões relevantes \\
\hline CATEGORIA - B & $\begin{array}{l}\text { Trabalho realizado de forma satisfatória com poucas omissões/inadequações } \\
\text { (no máximo } 2 \text { omissões/inadequações irrelevantes) }\end{array}$ \\
\hline CATEGORIA - C & $\begin{array}{l}\text { Trabalho considerado satisfatório, embora apresente algumas } \\
\text { omissões/inadequações (no máximo } 3 \text { omissões/inadequações irrelevantes) }\end{array}$ \\
\hline CATEGORIA - D & $\begin{array}{l}\text { Algumas partes foram bem atendidas, mas no todo o trabalho é considerado } \\
\text { insatisfatório (no máximo } 1 \text { omissão/inadequação relevante) }\end{array}$ \\
\hline CATEGORIA - E & $\begin{array}{l}\text { Trabalho insatisfatório, revelando omissões/inadequações relevantes } \\
\text { (no máximo } 2 \text { omissões/inadequações relevantes) }\end{array}$ \\
\hline CATEGORIA - F & $\begin{array}{c}\text { Trabalho extremamente insatisfatório, com etapas básicas mal atendidas } \\
\text { (no máximo } 3 \text { omissões/inadequações relevantes) }\end{array}$ \\
\hline CATEGORIA - G & Critério não atendido como um todo \\
\hline
\end{tabular}

2. Os critérios de revisão da qualidade adotados foram organizados em 6 seções que buscaram representar as etapas sequenciais básicas previstas para processos de AAE:

- Seção 1 - Descrição da base de dados ambientais (baseline) e integração com o processo de elaboração do SAGE;

- Seção 2 - Identificação e avaliação de questões-chave;

- $\quad$ Seção 3 - Determinação da significância dos impactos;

- $\quad$ Seção 4 - Processo de consulta;

- Seção 5 - Apresentação e divulgação dos resultados;

- Seção 6 - Recomendações sobre as alternativas preferenciais e monitoramento.

Assim, após a avaliação do atendimento aos critérios de revisão da qualidade, procedeu-se à avaliação qualitativa, caso a caso, do desempenho dos Relatórios em cada uma das 6 (seis) seções. Para tanto, novamente, utilizou-se da escala de avaliação da Tabela 3. Ressalta-se que, a referida escala de avaliação segue a lógica das revisões da qualidade da AIA, introduzida pela primeira vez por Lee \& Colley (1987). Nessa abordagem, o desempenho dos Relatórios nas seções é avaliado, a partir da visão geral que emerge da avaliação dos critérios de revisão, de forma que, o desempenho dos Relatórios nas seções não representa a média de seu desempenho nos critérios de revisão. Por exemplo, considerando-se a Seção 4 (processo de consulta), se o relatório foi classificado como (A) para os dois primeiros critérios, significa que fornece evidências de que as autoridades foram consultadas e que o relatório ambiental foi disponibilizado ao público. Porém, se nenhuma evidência foi fornecida sobre como as informações obtidas na consulta pública foram consideradas na tomada de decisão (classificação G para o critério), a seção de consulta terá obtido uma classificação geral de no máximo (D), uma vez que um critério relevante não foi atendido. Portanto, um desempenho muito baixo em um dos critérios de uma dada seção pode resultar em um desempenho baixo na seção como um todo, sugerindo que pouco esforço adicional é necessário para efetiva melhoria do desempenho na seção. Ademais, embora determinados critérios apresentem uma importância relativa maior no conjunto de critérios de uma mesma seção, escala de avaliação definida permitem a precisa classificação dos Relatórios segundo o desempenho nas seções.

3. Posteriormente, com base na avaliação geral que emergiu de seu desempenho nas seções, cada relatório foi também classificado, de acordo com a categoria de desempenho mais representativa de sua qualidade geral. Destaca-se que, mais do que a análise comparativa do desempenho individual dos processos de AAE, buscou-se com a revisão da qualidade dos Relatórios a identificação do estado atual geral do sistema francês de AAE de SAGEs. Além disso, por meio da análise da frequência dos relatórios com desempenho satisfatório (classificações $\mathrm{A}, \mathrm{B}$ e $\mathrm{C}$ ) nas seções, tidas como categorias de análise da prática francesa de AAE de SAGEs por representarem etapas fundamentais do processo de AAE, foi possível identificar as oportunidades e os desafios da prática francesa de AAE de SAGEs.

4. A partir da descrição dos critérios de revisão da qualidade mais atendidos pelo conjunto de Relatórios, foram identificados os métodos, ferramentas e abordagens analíticas passíveis de assimilação por eventuais AAEs de PBHs elaborados no Brasil. Por outro lado, a descrição dos 
critérios de revisão da qualidade menos atendidos pelos Relatórios possibilitou a identificação de limitações metodológicas e de abordagem analítica da prática francesa e que, devido às similaridades entre os sistemas francês e brasileiro de gestão dos recursos hídricos, podem também limitar o desempenho de uma AAE eventualmente aplicada a um PBH do Brasil. Por fim, considerando-se as boas práticas do sistema francês e os mecanismos sugeridos na literatura para a superação das limitações das AAEs de SAGEs, foram identificadas as potenciais contribuições da AAE para os PBHs do Brasil.

\section{RESULTADOS E DISCUSSÕES}

\subsection{Qualidade dos Relatórios de AAEs aplicadas aos SAGEs - uma visão geral}

O Quadro 3 apresenta os resultados da avaliação geral dos Relatórios de AAEs, enquanto a Figura 1 apresenta a distribuição do conjunto de Relatórios de conforme a categoria de desempenho alcançada na avaliação geral.

Quadro 3. Desempenho dos Relatórios de AAE nas seções e avaliação geral.

\begin{tabular}{|c|c|c|c|c|c|c|c|}
\hline \multirow{2}{*}{ Relatório de AAE } & \multicolumn{6}{|c|}{ Desempenho nas seções consideradas } & \multirow{2}{*}{ Avaliação gera } \\
\hline & 1 & 2 & 3 & 4 & 5 & 6 & \\
\hline 1. Celé & B & $\mathbf{C}$ & D & D & $\mathbf{A}$ & B & C \\
\hline 2. Estuaire de la Gironde & B & D & $\mathbf{E}$ & $\mathbf{C}$ & $\mathbf{A}$ & $\mathbf{C}$ & C \\
\hline 3. Canche & D & D & $\mathbf{D}$ & $\mathbf{C}$ & $\mathbf{A}$ & $\mathbf{C}$ & D \\
\hline 4. Delta de I'Aa & $\mathbf{C}$ & $\mathbf{C}$ & $\mathbf{E}$ & B & B & D & D \\
\hline 5. Etang de Biguglia & B & B & $\mathbf{E}$ & $\mathbf{E}$ & $\mathbf{A}$ & $\mathbf{A}$ & C \\
\hline 6. Baie de Saint - Brieuc & $\mathrm{C}$ & D & D & $\mathbf{C}$ & $\mathbf{A}$ & $\mathbf{E}$ & $D$ \\
\hline 7. Sioule & A & C & D & B & $\mathbf{A}$ & D & $C$ \\
\hline 8. Ill Nappe Rhin & B & B & $\mathbf{C}$ & B & $\mathbf{A}$ & $\mathbf{C}$ & $B$ \\
\hline 9. Bassin ferrifère & B & $\mathbf{A}$ & B & B & $\mathbf{A}$ & B & $A$ \\
\hline 10. Drôme & $\mathbf{B}$ & $\mathbf{C}$ & $\mathbf{C}$ & $\mathbf{E}$ & $\mathbf{A}$ & $\mathbf{A}$ & $C$ \\
\hline 11. Aisne Vesle Suippe & $\mathbf{A}$ & B & $\mathbf{C}$ & C & $\mathbf{A}$ & $\mathbf{C}$ & $B$ \\
\hline 12. Cailly, Aubette, Robec & A & B & $\mathbf{C}$ & C & $\mathbf{A}$ & $\mathbf{C}$ & $B$ \\
\hline
\end{tabular}

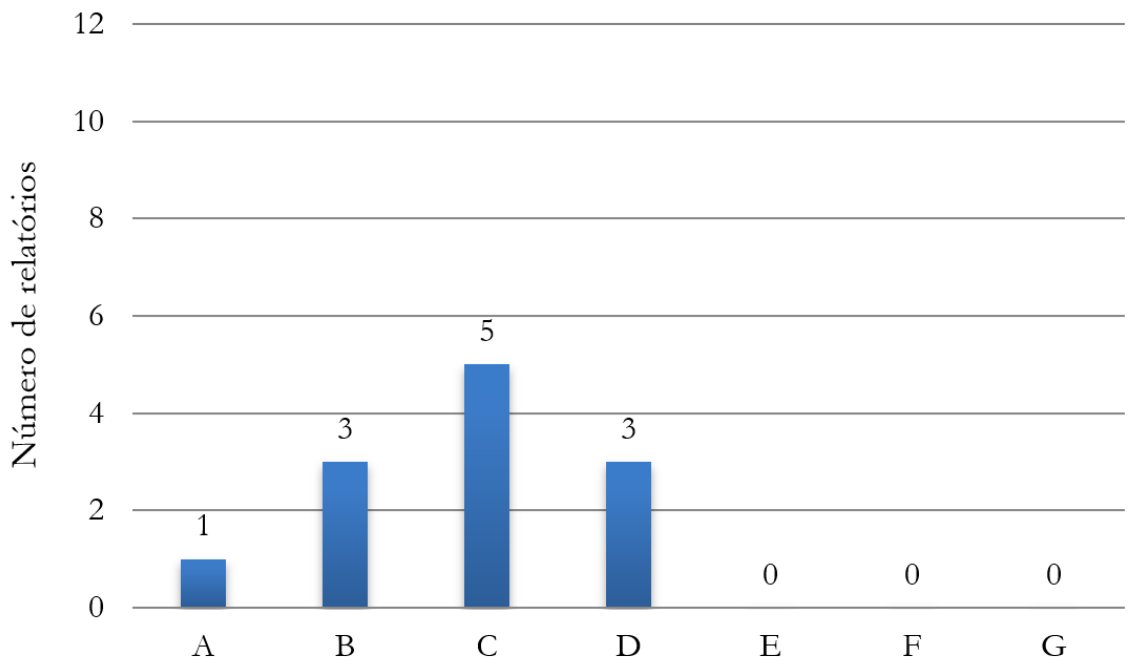

Figura 1. Distribuição dos Relatórios de AAE conforme a categoria de desempenho na avaliação geral.

Por meio da Figura 1, verifica-se que 9 dos 12 Relatórios de AAE revisados apresentaram desempenho satisfatório (categoria de desempenho igual ou superior a " $C$ "), sendo que apenas 1 recebeu avaliação geral "A" (trabalho bem realizado, sem omissões/inadequações relevantes). 
Por outro lado, 3 Relatórios receberam avaliação geral "D”, o que significa dizer que, nestes casos, embora alguns critérios tenham sido atendidos, no todo o trabalho foi considerado insatisfatório.

As Figuras 2 e 3, em seguida, descrevem o desempenho dos relatórios em cada uma das 6 categorias de análise consideradas (seções), fornecendo uma visão mais detalhada dos resultados. Enquanto a Figura 2 apresenta a proporção de relatórios nas diferentes classes de desempenho, a Figura 3 apresenta a proporção de Relatórios com desempenho satisfatório em cada uma das seções.

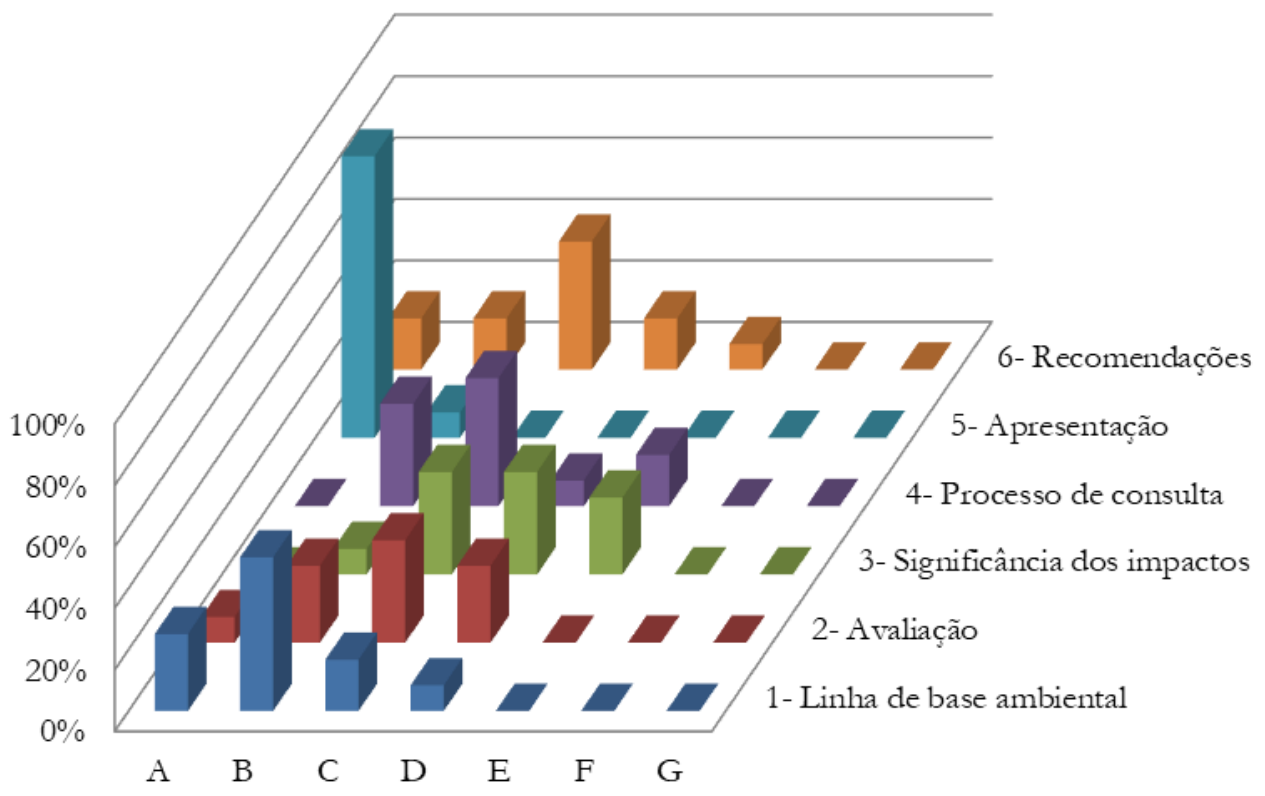

Figura 2. Proporção de Relatórios de AAE nas classes de desempenho, considerando-se as 6 seções consideradas.

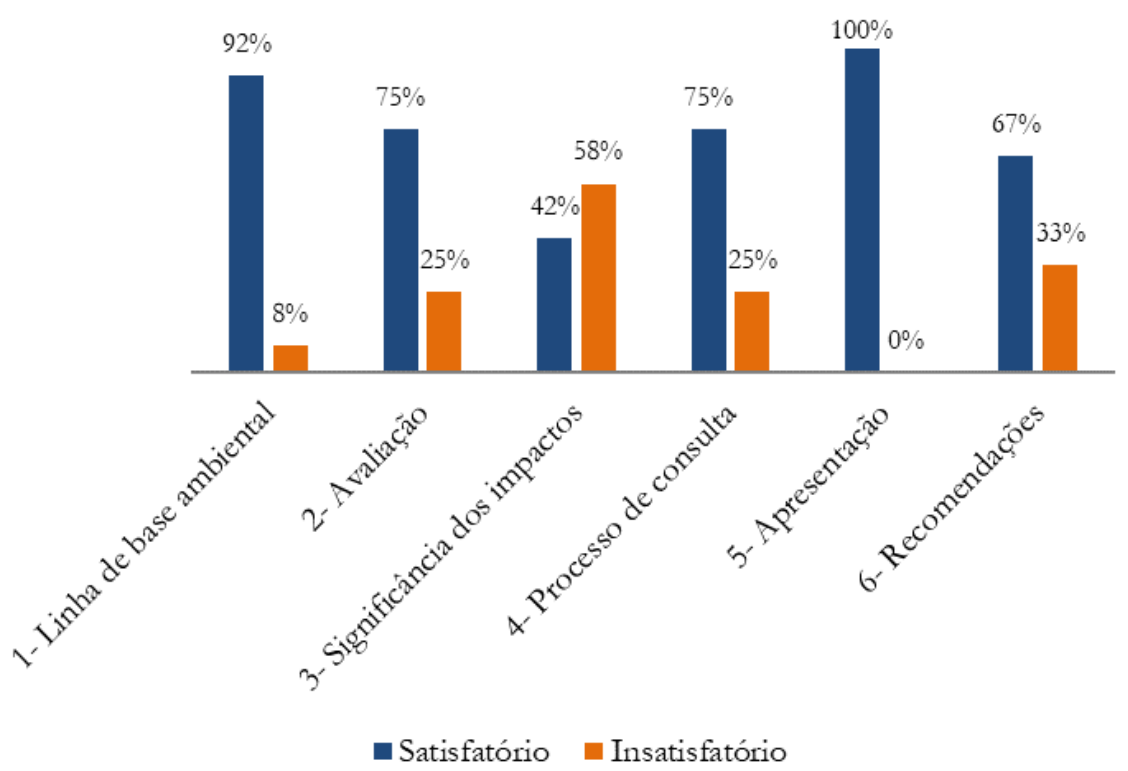

Figura 3. Proporção de Relatórios de AAE com desempenho satisfatório nas seções consideradas.

Observa-se que os Relatórios de AAE obtiveram melhor desempenho nas seções 1 (Linha de base ambiental e integração com o processo de AAE) e 5 (Apresentação e informação dos resultados), que contabilizaram, respectivamente, uma proporção de $92 \%$ e $100 \%$ dos relatórios com qualidade satisfatória. Vale destacar o bom desempenho dos Relatórios nas seções 2 (Avaliação e questões-chave) e 4 (Processo de consulta), que apresentaram 75\% dos relatórios com qualidade satisfatória. Contudo, a seção 3 (Determinação da significância dos impactos) apresentou o maior percentual de relatórios com desempenho insatisfatório, com 58\% deles nesta categoria. Por fim, uma parcela (33\%) dos 
relatórios obteve desempenho insatisfatório na seção 6 (Recomendações sobre alternativas preferenciais e monitoramento).

O bom desempenho dos Relatórios de AAE na seção 1 evidenciou a disponibilidade de dados e informações relativas aos temas priorizados pelos SDAGEs e a preocupação das AAEs de SAGEs quanto ao atendimento às diretrizes da Diretiva Europeia sobre AAE. Aqui, convém destacar outras duas características das AAEs de SAGEs, identificadas com a revisão dos Relatórios selecionados:

(i) A influência da DQA na estruturação das AAEs das estratégicas de planejamento e gestão dos recursos hídricos, que exige das AAEs de SAGEs a consideração do contexto mais amplo de gestão, tendo em vista a definição de diretrizes para alcance dos objetivos de qualidade impostos aos Estados-membros.

(ii) A etapa de definição do escopo das AAEs de SAGEs focada nos temas identificados nos SDAGEs, que exerceu forte influência nos dados coletados para a identificação da linha de base ambiental e, embora tenha contribuído para o desempenho satisfatório dos Relatórios na seção 2, relativa à avaliação das questões ambientais-chave, direcionou os Relatórios para discussões mais gerais e inespecíficas, limitando a busca por informações relativas às questões ambientais de maior relevância no nível local.

Conforme Lee (2006), Fischer (2007), Arts et al. (2011), este encadeamento dos diferentes níveis estratégicos de planejamento, associado ao conceito de "tiering" ou avaliação em cascata ${ }^{4}$, exerce significativa influência sobre as questões de escala, escopo e levantamento de informações, estabelecendo uma estrutura mais favorável à avaliação, uma vez que as ações estratégicas em análise teriam respaldo em referências anteriores, em nível mais abrangente de avaliação. Embora a identificação da linha de base ambiental focada em objetivos e questões previamente definidos simplifique a tarefa muitas vezes exaustiva de levantamento de informações, a eficácia desse procedimento está, contudo, condicionada à relevância dos objetivos estratégicos definidos e à pertinência dos indicadores selecionados (Fry et al., 2002).

Therivel (2004) classifica os processos de AAE segundo a abordagem empregada na avaliação dos impactos ambientais, que contempla a previsão dos impactos da Política, Plano ou Programa em desenvolvimento e a avaliação da significância dos impactos previstos. A previsão dos impactos é consequência das etapas de identificação da linha de base ambiental (seção 1) e de definição do escopo da AAE (seção 2), enquanto a avaliação da significância dos impactos corresponde aos procedimentos empregados para análise da importância dos impactos previstos (seção 3). Conforme Sánchez (2006), por implicar um juízo de valor sobre a importância social atribuída a determinado fatores ambientais e ecossistêmicos, a avaliação da significância dos impactos só se concretizará após os procedimentos de consulta pública (seção 4).

Nesse sentido, há duas perspectivas diferentes para a avaliação dos impactos ambientais: (i) uma abordagem mais exaustiva (baseline-led) que busca o conhecimento detalhado na área de estudo, e pressupõe que quanto maior a quantidade de informações levantadas, melhor será a avaliação dos impactos e; (ii) uma abordagem mais focada (objective-led) e dirigida por objetivos regionais de sustentabilidade previamente definidos em níveis anteriores da hierarquia de planejamento, e que pressupõe que as alternativas de desenvolvimento propostas possam ser avaliadas segundo o grau de atendimento a tais objetivos (Fry et al., 2002).

Depreende-se do exposto que, os objetivos da AAE podem derivar tanto de ações estratégicas anteriores quanto dos dados coletados para a identificação da linha de base ambiental. De outra forma, em situações onde não existam objetivos estratégicos definidos ou nenhuma avaliação ambiental anterior tenha sido realizada, ou ainda, onde não haja informações suficientes para a identificação da linha de base ambiental, os objetivos da AAE não poderão ser identificados (Azcarate \& Balfors, 2009). Nesses casos, uma possível solução seria a definição dos objetivos da AAE por meio de consulta aos atores interessados (Therivel, 2004), uma vez que, mesmo em abordagens sistemáticas e orientadas por objetivos, a participação pública fornece uma visão política crucial, que torna o processo de AAE mais eficiente e confiável (Fischer, 2003).

Confrontando-se essas constatações com a revisão dos Relatórios de AAEs de SAGE, entende-se que, embora a orientação e prática da AAE em um nível anterior da hierarquia de planejamento, na ocasião da elaboração dos SDAGEs, estabeleça um contexto mais favorável para a avaliação de impacto

\footnotetext{
${ }^{4}$ Segundo Arts et al. (2011, p. 417) o conceito de "tiering" diz respeito à transferência deliberada e organizada de informações e questões entre as estratégias de níveis subsequente na hierarquia de planejamento, tendo em vista o estabelecimento de uma sequência mais eficiente de Avaliação de Impacto, dos níveis estratégicos aos mais operacionais.
} 
ambiental, a abordagem mais direcionada a temas estratégicos, definidos na DQA e nos SDAGEs, conduziu as AAEs de SAGEs ao levantamento e utilização de informações em escala mais ampla, inapropriada para as decisões no âmbito local, aspectos que associados a um processo tardio de consulta pública contribuíram para o desempenho insatisfatório dos Relatórios na seção 3, relativa à avaliação da significância dos impactos previstos.

Assim, apesar de todos os Relatórios cumprirem os requisitos da Diretiva europeia sobre AAE, em algumas situações, dadas as especificidades da área de influência do SAGE, nem todas as questões priorizadas contribuíram com informações relevantes à tomada de decisão, nesses casos, os Relatórios de AAE não traziam evidências de que todas as informações compiladas na etapa de caracterização da linha de base ambiental foram utilizadas para avaliação e classificação dos impactos previstos, segundo a importância relativa de cada um deles (significância), sugerindo que os esforços direcionados para a coleta de dados e informações relativos a temas irrelevantes no âmbito local poderiam ter sido direcionados para a descrição e análise de outras questões, com maior significado para a AAE.

A determinação da significância dos impactos é frequentemente apontada como um dos pontos frágeis da prática de AAE (Fischer, 2010; Lemos et al., 2012; Bragagnolo et al., 2012; Bragagnolo \& Geneletti, 2012; Montis, 2014). Resultados similares foram observados em outros estudos que se utilizaram das mesmas categorias de análise do presente artigo para a revisão de relatórios de AAE de estratégias de uso e ocupação do solo em outros países europeus (Jiricka \& Probstl, 2008; Fischer, 2010): um alto desempenho dos Relatórios na seção 1 - Linha de base ambiental e integração com SAGE contrapondo-se a um baixo desempenho na seção 3 Determinação da significância dos impactos.

Para Fischer (2010), os esforços despendidos na estruturação de uma extensa base de dados ambientais, frequentemente não conduzem a uma avaliação consistente, com a devida descrição e interpretação dos impactos secundários, cumulativos e sinérgicos das alternativas propostas, dificultando o estudo da significância dos impactos. Jiricka \& Probstl (2008), ao examinarem a maneira pela qual a Diretiva da AAE foi incorporada na Áustria, na Alemanha, na Itália de na França, identificaram, por meio de entrevista a especialistas e praticantes da AAE que, embora quantidade de dados ambientais disponíveis seja suficiente para a estruturação de uma base de dados consistente, a seleção e padronização dos dados coletados constituem desafios a serem superados.

Assim, embora os sistemas de AAE orientados por objetivos previamente estabelecidos, como sistema francês de AAE de SAGEs, favoreçam os procedimentos para a caracterização da linha de base ambiental (Therivel, 2004), a depender da robustez desses objetivos e das questões priorizadas, o processo de avaliação pode se tornar tendencioso, com soluções pouco criativas, por não considerar outras questões ambientais significativas (Azcarate \& Balfors, 2009).

Bragagnolo \& Geneletti (2012), ao analisarem a abordagem dos efeitos cumulativos em AAEs de estratégias de planejamento territorial da Itália e da Inglaterra, apontaram a definição do escopo e o uso de informações georreferenciadas como fatores críticos, que condicionam o sucesso da abordagem dos impactos cumulativos. Por sua vez, a participação pública é também reconhecida pela comunidade científica como um mecanismo que agrega transparência e legitimidade às decisões tomadas, ampliando os resultados obtidos na determinação da significância dos impactos previstos (Rega \& Baldizzone, 2014; Monteiro \& Partidário, 2017).

No entanto, conforme destacam Azcarate \& Balfors (2009), a maioria dos sistemas de AAE, incluindo a Diretiva Europeia da AAE, inclui apenas requisitos mínimos para a participação pública, limitando-se a procedimentos tardios de revisões de Relatórios de AAEs (Therivel, 2004). Os resultados aqui obtidos corroboram tais afirmações: embora a maior parte dos Relatórios analisados tenha obtido desempenho satisfatório na seção 4 - Processo de consulta, não foram observados procedimentos que viabilizassem o envolvimento público nas etapas iniciais de definição de objetivos e delimitação do escopo da AAE.

Embora a estruturação de processos participativos de AAE constitua tarefa difícil de ser realizada, principalmente em níveis estratégicos de tomada de decisão (Dalkmann et al., 2004; Chaker et al., 2006), entende-se que, no caso das estratégias de desenvolvimento dos recursos hídricos, que buscam conciliar os interesses muitas vezes conflitantes em seus usos, uma abordagem participativa de AAE deve ser priorizada (Sinclair et al., 2009), com benefícios relacionados à aprendizagem social e compreensão compartilhada de valores, dada a abertura a diferentes visões e argumentos que favorecem uma decisão consensual (Connelly \& Richardson, 2005).

Por fim, apesar da maior parte dos Relatórios analisados ter apresentado desempenho satisfatório na seção 6 - Recomendação sobre alternativas preferenciais e monitoramento, 33\% dos Relatórios apresentaram significativas inconsistências quanto a esses procedimentos. A insuficiente 
descrição dos métodos e procedimentos de monitoramento a serem empregados é também descrita em outros estudos relacionados de revisão da prática de AAE (Jiricka \& Probstl, 2008; Fischer, 2010; Lemos et al., 2012). Contudo, vale destacar que o sistema francês de AAE prevê a realização e revisão anual de um painel para a comunicação e informação pública sobre os indicadores que serão utilizados no acompanhamento dos SAGEs aprovados: o tableau de bord des SAGE.

O tableau de bord dos SAGEs contempla um atlas cartográfico, com cartas temáticas de indicadores ambientais baseados no modelo conceitual Pressão - Estado - Resposta (Organization for Economic Cooperation and Development, 2003), além de breve descrição dos métodos de monitoramento adotados. Assim, levando em consideração os resultados do Relatório Ambiental da AAE, o tableau de bord informa os resultados obtidos com a implementação dos SAGEs, bem como o alcance das metas pretendidas.

A revisão e as discussões aqui realizadas sugerem que a exigência de tal documento pode ter influenciado o conteúdo de alguns Relatórios de AAE, os quais, por vezes, limitaram-se a informar que o monitoramento do SAGE se daria conforme diretrizes legais relativas ao tableau de bord. Entretanto, tanto a Diretiva Europeia sobre AAE quanto o Código Ambiental francês preveem a descrição do processo de monitoramento como parte integrante do conteúdo dos Relatórios de AAE e, dessa forma, entende-se que os Relatórios revisados deveriam apresentar tais informações, sendo ausência delas, portanto, uma lacuna de informação que contribuiu para o desempenho insatisfatório de parte dos Relatórios revisados.

\subsection{Oportunidades e desafios do sistema francês de AAE de SAGEs}

Conforme Partidário (2007), os processos de AAE geralmente apresentam elementos técnicos e metodológicos que decorrem do aprendizado com a prática de elaboração de políticas ou da experiência com a aplicação da AIA, permitindo a identificação de dois conjuntos principais de abordagens procedimentais para esse instrumento: (i) abordagens top-down ou strategic-based, que adotam a lógica do planejamento e avaliação de políticas públicas, identificando necessidades e opções de desenvolvimento, numa visão de desenvolvimento sustentável e; (ii) abordagens bottom-up ou EIA-based, que, como uma extensão da AIA de projetos, incluem o levantamento de informações e alguma metodologia de avaliação e comparação de alternativas, bem como a proposição de medidas de mitigação dos impactos negativos e monitoramento.

Assim, se por um lado o sistema francês de gestão de recursos hídricos evoluiu de forma a estruturar um processo de gestão orientada por objetivos, no qual os SAGEs assumem o papel de instrumento local de declinação da DQA, com caráter mais prescritivo que operacional (Berreta et al., 2012; France, 2012), por outro, a incorporação dos preceitos da Diretiva europeia sobre AAE ao arcabouço legislativo francês se deu de forma a regulamentar um processo de AAE com procedimentos(técnicos e metodológicos) similares aos da Avaliação de Impacto Ambiental (AIA) de projetos e, nesse sentido, a abordagem do sistema francês de AAE de SAGEs pode também ser definida com uma abordagem EIA-based.

Entretanto, diferentemente de um contrato de rio ${ }^{5}$, que é instrumento de programação operacional, o SAGE constitui momento privilegiado para discussão entre os atores no sentido da solução de conflitos na sub-bacia hidrográfica, formalizando os objetivos e as regras a serem perseguidas pelos membros das Comissões Locais de Água. Além disso, sendo a elaboração de um SAGE procedimento facultativo na maioria dos casos, sua implementação deve, em princípio, ser a expressão da vontade política das coletividades territoriais ${ }^{6}$ (Lanna et al., 2002). Por fim, embora a construção dos SAGEs seja orientada por objetivos de desenvolvimento sustentável, não se pode perder de vista o papel que a AAE no processo de antecipação dos efeitos dos SAGEs em outros compartimentos ambientais, além das águas e dos ambientes aquáticos, atuando na construção e avaliação dos cenários considerados (MEEDDAT - ACTeon, 2012).

Portanto, diante dos resultados aqui obtidos, entende-se que no caso das AAEs de SAGEs uma abordagem mais próxima das abordagens strategic-based poderia desempenhar um papel mais efetivo na construção de um plano de ação e gestão sustentável, no recorte das sub-bacias e sistemas de aquíferos, numa abordagem proativa na construção do futuro desejado, orientando o processo de

\footnotetext{
${ }^{5}$ Instrumento complementar de planejamento e gestão dos recursos hídricos, que envolve contratualmente o Estado, a Agência de Água ou as Coletividades territoriais, no papel de financiadores, e os responsáveis (públicos ou privados) pelos projetos que concretizarão o plano de desenvolvimento e gestão sustentável definido no âmbito dos SAGEs.

${ }^{6}$ Compostas por comunas, departamentos e regiões - constituem circunscrições administrativas dotadas de personalidade jurídica que, conforme Lanna et al. (2002), após as Leis francesas de Descentralização de 1982 e 1983, tornaram-se as principais operadoras em matéria de matéria de saneamento, abastecimento de água potável e gestão dos cursos de água.
} 
planejamento com critérios e indicadores legítimos de sustentabilidade ambiental. Nesse contexto, a AAE desempenharia o papel de instrumento estratégico de orientação, que - diferentemente de uma AAE de abordagem mais programática e até mesmo de uma AIA de projetos, cujo intuito é avaliar e mitigar os efeitos de projetos pontuais sobre o ambiente - está mais preocupado com a ampla compreensão dos problemas na área de estudo e o alinhamento das estratégias de desenvolvimento com os objetivos de sustentabilidade previamente definidos (Partidário, 2007).

Ressalta-se que, embora a AAE de base estratégica esteja mais preocupada com o alinhamento das estratégias, tendo em vista a solução dos problemas anunciados, a avaliação das consequências ambientais significativas pode ser realizada observando-se, por exemplo, as implicações globais, regionais ou locais da estratégia em desenvolvimento. Outra possibilidade é a promoção da melhoria da qualidade ambiental, que pode ser alcançada por meio da adequada avaliação e promoção dos efeitos positivos da estratégia em desenvolvimento (McCluskey \& João, 2011).

Com auxílio da Figura 4, que apresenta a classificação média dos critérios de qualidade adotados, considerando-se todos os Relatórios revisados, observa-se que o critério 16, relativo à avaliação da influência do SAGE nos níveis subsequentes da hierarquia de planejamento, não foi atendido como um todo - categoria "G" de desempenho, sugerindo que, embora no critério 2, relativo a prestação de informações sobre a relação do SAGE com outros planos e programas setoriais relevantes, os Relatórios tenham realizado um bom trabalho, sem omissões relevantes - categoria " $A$ " de desempenho, estes não foram capazes de informar como os SAGEs, por meio de suas diretrizes e recomendações, influenciariam programas e projetos futuros, relacionados ao setor de recursos hídricos, em termos de localização, condições ou alocação de recursos, por exemplo. Em outras palavras, os Relatórios não foram capazes de evidenciar o tiering entre o SAGE as estratégias futuras de desenvolvimento dos recursos hídricos.

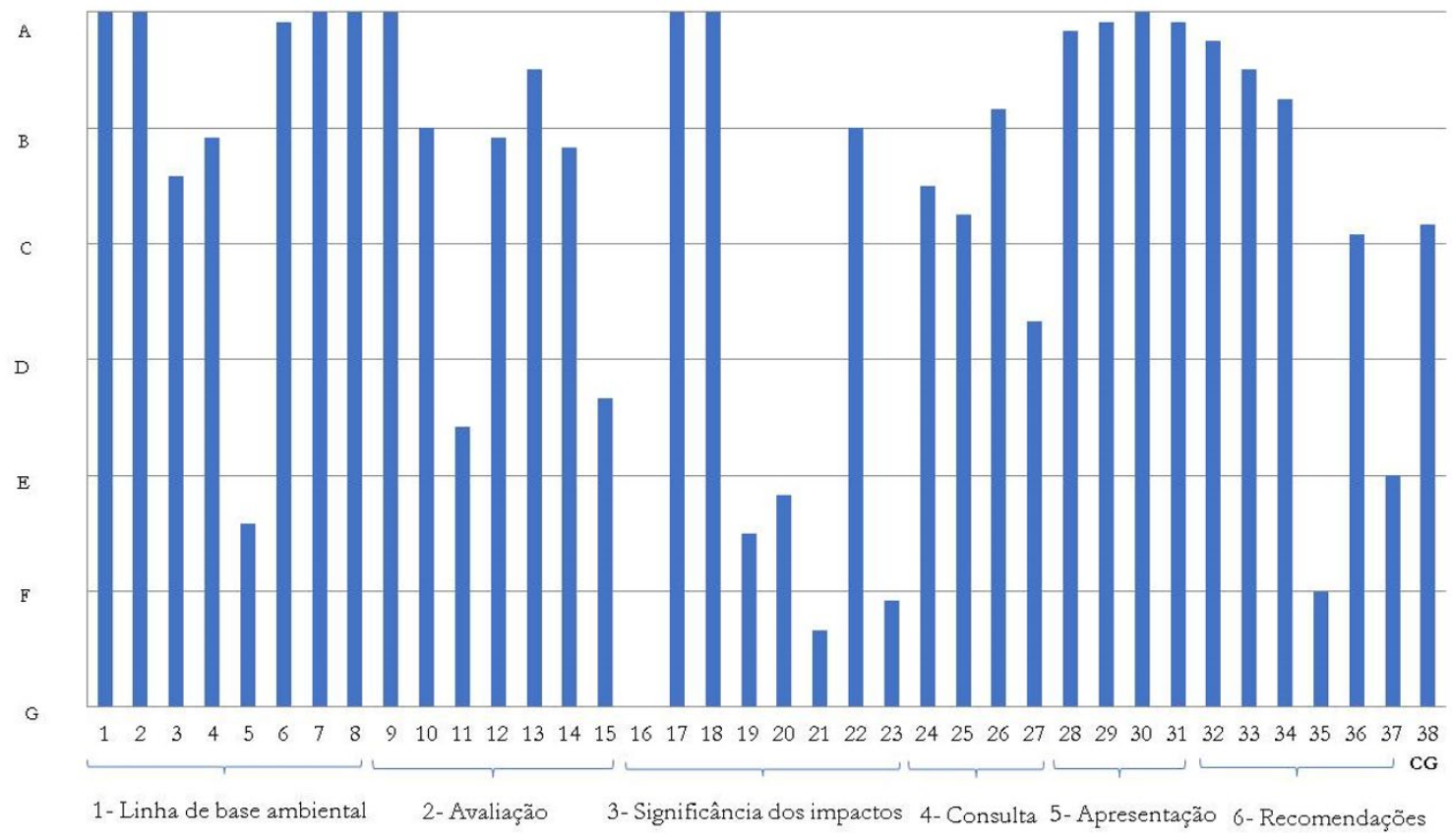

Figura 4. Classificação média dos Relatórios em todos os 37 critérios de revisão utilizados (38=Classificação Global média)

Além disso, embora o critério 20, relativo aos efeitos secundários, cumulativos e sinérgicos das alternativas, e o critério 23, relativo à magnitude e extensão geográfica dos efeitos identificados, não tenham sido contemplados de forma satisfatória nos Relatórios, estes não justificam o baixo desempenho na seção 3, pois, conforme descrito anteriormente há outras possibilidades para a avaliação das consequências ambientais significativas. Acrescenta-se que, no caso do critério 23, relativo à identificação da magnitude e extensão espacial dos impactos ambientais, de fato, nenhum Relatório utilizou-se de informações georreferenciadas ou outro procedimento que contribuísse para o bom desempenho nesse critério, sendo a matriz de interação a ferramenta de avaliação mais utilizada. 
O desempenho dos Relatórios no critério 35 (A AAE descreve como efeitos positivos do Plano podem ser maximizados?), por exemplo, evidencia uma abordagem limitada dos efeitos positivos dos SAGEs, dado que os mecanismos de maximização dos ganhos ambientais não foram apropriadamente discutidos, de forma a influenciar a seleção e/ou priorização de estratégias futuras de desenvolvimento. Argumenta-se, portanto, que a significância dos efeitos dos SAGEs em desenvolvimento poderia ter sido avaliada por meio de outros procedimentos, como, por exemplo, a identificação da transferência adequada de informações do SAGE para outras ações estratégicas subsequentes na hierarquia de planejamento.

Nesse sentido, justifica-se sobre a importância da consistente análise de objetivos e definição das questões-chave de avaliação, durante a etapa de definição do escopo da AAE (Harding, 1998; Singleton et al., 1999; Wood, 2000; Stookes, 2003; Sánchez, 2006) que, para além da consideração exclusiva dos requisitos legais e diretrizes técnicas das autoridades ambientais, pode se a utilizar de abordagens inovadoras de construção participativa, com amplo envolvimento das diversas partes interessadas, incluindo a vertente comunitária (Azcarate \& Balfors, 2009; Polido et al., 2016).

Conforme Polido \& Ramos (2015); Noble \& Nwanekezie (2017), a AAE é um processo contexto-específico e, portanto, deve se adaptar ao sistema político e de planejamento existente, ao tipo de decisão abordada, bem como ao contexto territorial. Segundo Azcarate \& Balfors (2009), em AAE, procedimentos participativos de diagnósticos favorecem a identificação de informações adicionais e demandas futuras, ampliando os resultados do processo de avaliação em regiões com lacuna de conhecimento e/ou objetivos setoriais conflitantes. Polido et al. (2016) defendem a necessidade de a AAE incorporar informações contextuais locais, incluindo o conhecimento intuitivo e senso de lugar da comunidade e dos especialistas locais.

Dessa maneira, por facilitar a identificação de critérios e indicadores de consenso entre as partes interessadas, refletindo os conflitos e problemas regionais, entende-se que uma abordagem participativa durante os procedimentos de definição do escopo da AAE facilitaria a determinação da significância dos efeitos dos SAGEs, bem como a identificação de objetivos e metas de sustentabilidade a serem integradas em outras ações estratégicas desenvolvimento (Therivel, 2004; Fischer, 2007).

Destaca-se, por fim, o valor agregado por três requisitos legais de AAE de SAGEs: a compatibilização entre objetivos estratégicos setoriais; o quadro de indicadores de monitoramento (tableau de bord), estruturado a partir dos resultados do processo de avaliação ambiental e; a Declaração Ambiental, documento sujeito à aprovação, que atesta a influência dos resultados do processo de consulta pública no conteúdo do Plano em desenvolvimento. Tais procedimentos, além de contribuírem para o processo de avaliação ambiental como um todo, ampliam os resultados obtidos com as AAEs dos SAGEs, fortalecendo o papel desses como instrumentos de planejamento da gestão francesa dos recursos hídricos.

\subsection{Potenciais contribuições da AAE para os Planos de Bacia Hidrográfica do Brasil}

A estrutura federativa, com duplo domínio das águas (federal e estadual) em uma mesma bacia hidrográfica, bem como as diferenças no estágio de desenvolvimento e implantação dos sistemas estaduais de recursos hídricos, são fontes de conflitos que geram entraves à efetiva gestão integrada dos recursos hídricos no Brasil (Lanna et al., 2000; Porto \& Porto, 2008). A necessidade de atuação nesse contexto demanda a priorização de instrumentos de planejamento que promovam as articulações vertical (entre o PBH elaborado e os Planos Estaduais e Nacional de recursos hídricos) e horizontal (entre o PBHs e outras estratégias setoriais correlacionadas com a gestão hídrica, tais como os planejamentos regionais e municipais de uso e ocupação do solo).

Nessa perspectiva, os Planos de Bacia Hidrográfica (PBHs) devem assumir o papel de instrumentos integradores, orientando a expansão do uso e ocupação do solo, integrando toda a dinâmica territorial que direta ou indiretamente influencia a qualidade e a quantidade dos recursos hídricos. Além disso, por atuar na escala regional, em ambiente multissetorial, espera-se que o processo de elaboração desses Planos possibilite a redução dos conflitos e impactos ambientais em sua área de abrangência, bem como o estabelecimento de objetivos regionais de desenvolvimento a serem compartilhados pelos diversos atores institucionais, locais e regionais.

No Brasil, a abordagem da sustentabilidade ambiental e da visão integrada na gestão dos recursos hídricos é preconizada pela PNRH, contudo, no processo de elaboração dos PBHs não são empregados procedimentos que induzam a busca explícita por alternativas de ação efetivamente sustentáveis. Além disso, a participação pública, de forma sistemática, é restrita às discussões no âmbito dos CBHs (Agra Filho \& Ramos, 2015). 
Ainda não regulamentada no Brasil, a AAE apresenta aplicação limitada no País, sendo predominantemente aplicada de forma voluntária para avaliar os efeitos ambientais de grandes projetos de desenvolvimento, em decorrência de requisitos impostos por agencias de fomento, ou para facilitar a aprovação de Estudos de Impacto Ambiental de grandes projetos de infraestrutura (Montaño et al., 2014). No caso específico do setor de recursos hídricos, destacam-se a utilização voluntária da AAE como suporte à elaboração do Plano de Recursos Hídricos da bacia Araguaia-Tocantins (Agência Nacional das Águas, 2008) e as recomendações do Plano de Recursos Hídricos da Região Hidrográfica do Paraguai, quanto à possibilidade de os órgãos gestores estaduais integrarem os resultados de estudos de balanço hídrico quali-quantitativo e outros relacionados à área de recursos hídricos com ferramentas voltadas à área ambiental, como AAE (Agência Nacional das Águas, 2017).

Por outro lado, a revisão da prática francesa demonstrou que: (i) a existência de objetivos de sustentabilidade previamente definidos não garante a eficácia das AAEs de PBHs, tampouco a construção de Planos integradores e; (ii) no caso de PBHs subsidiados por processos de AAE, abordagens tardias de envolvimento público podem comprometer a etapa de avaliação da significância dos impactos ambientais previstos, tornando os PBHs demasiadamente genéricos e pouco operacionais.

Portanto, considerando-se o caráter operacional dos PBHs do Brasil, a ausência de avaliações ambientais em níveis anteriores da hierarquia de planejamento, bem como a relatada ausência de informações ambientais em quantidade e escala apropriada às decisões no âmbito das bacias hidrográficas (Pizella \& Souza, 2013; Vasconcelos, 2013), entende-se que uma abordagem sistemática de AAE (nos moldes da Diretiva Europeia sobre AAE) que, contudo, empregasse procedimentos antecipados de envolvimento público, ampliaria a capacidade comunicativa do processo de elaboração de PBHs, favorecendo a construção de Planos mais alinhados à dinâmica territorial da bacia hidrográfica.

Uma evidência disso foi o bom desempenho de todos os Relatórios de AAEs de SAGEs no atendimento aos critérios 2, relativo à prestação de informações sobre a relação do SAGE com outros planos e programas relevantes, e 8, relativo à ponderação de objetivos e estratégias de proteção ambiental adotados internacionalmente, na Europa ou na França, que só foi possível devido à aplicação de procedimentos de análise da consistência (conformidade e compatibilidade) dos objetivos do SAGE frente aos objetivos de outras Políticas, Planos e Programas (PPPs) intervenientes na gestão dos recursos hídricos.

Acrescenta-se que, se realizada no âmbito de um processo participativo de identificação da linha de base ambiental, a análise de consistência permite a contextualização do PBH na dinâmica territorial da bacia hidrográfica, constituindo oportunidade para estabelecimento das preconizadas articulações vertical e horizontal. Além disso, no caso de temas convergentes, o PBH poderia se beneficiar do diagnóstico realizado por outros Planos e Programas regionais, evitando-se a duplicação de coleta e tratamento de dados (Pizella \& Souza, 2013).

No caso específico da articulação (horizontal) entre os PBHs e os Planos Diretores Municipais por meio da AAE, Pizella (2019) descreve outras potencialidades relacionadas às questões institucionais: (i) os representantes das prefeituras municipais têm representação assegurada no âmbito dos CBHs; (ii) o Estatuto da Cidade, Lei No. 10.257/2001 que estabelece as diretrizes gerais da política urbana no Brasil, preconiza a consideração dos PBHs no processo de elaboração dos Planos Diretores e; (iii) as etapas sequenciais básicas previstas para o desenvolvimento da AAE são completamente compatíveis com as etapas previstas para a elaboração de ambos os Planos.

Definido como procedimento obrigatório em AAEs de SAGEs, a análise de consistência é frequentemente realizada por meio da utilização de ferramentas qualitativas de análise, como os quadros de estrutura lógica, que confrontam os diferentes objetivos ambientais e de sustentabilidade transversais às diferentes PPPs com os objetivos e conteúdo das mesmas. Para exemplos de estruturação e aplicação de quadros de estrutura lógica, ver Leone \& Zoppi (2019).

Para além da simples compatibilização entre objetivos estratégicos, com a AAE, há ainda a possibilidade de os PBHs funcionarem como balizadores de outras estratégias (setoriais, regionais ou locais) de uso dos recursos hídricos, uma vez que, ao longo dos procedimentos previstos para o desenvolvimento da AAE são identificados critérios de sustentabilidade ambiental que podem informar outros processos decisórios setoriais, no sentido da sustentabilidade no uso dos recursos hídricos. Conforme Pizella \& Souza (2013), a existência de Comitês de Bacia Hidrográfica (CBHs) é, nesse sentido, muito vantajosa. Com composição que envolve os órgãos da administração pública em âmbito estadual e municipal e, setores usuários da água, os CBHs constituem fóruns adequados à identificação das demandas e dos conflitos setoriais relacionados aos usos dos recursos hídricos. 
Contudo, a existência de CBHs não é garantia de efetiva participação pública, uma vez que, no Brasil, a participação da sociedade civil no CBHs é bastante limitada e desprovida de recursos institucionais que possam influenciar nas definições finais (Malheiros et al., 2013; Pizella \& Souza; 2013; Agra Filho \& Ramos, 2015; Jacobi et al., 2015). Assim, embora a participação pública seja procedimento previsto em todas as etapas de elaboração dos PBHs, a participação da sociedade civil está condicionada às medidas operacionais que venham a ser praticadas no âmbito dos CBHs e às abordagens empregadas pelas consultorias contratadas para a elaboração/revisão desses planos, sob risco de se tornar essencialmente passiva e pouco inclusiva. Assim, admitir que a participação pública no âmbito dos CBHs seja suficiente para lidar com a complexidade do planejamento de recursos hídricos é decisão que pode comprometer não só a efetividade dos PBHs, mas a gestão dos recursos hídricos como um todo, que pressupõe a atuação com transparência por meio de estratégias de comunicação e divulgação de amplo espectro (Jacobi et al., 2015).

De outra parte, pela revisão da prática francesa, observou-se que embora as análises de consistência, ampliem a racionalidade comunicativa do processo de AAE, elas não garantem as efetivas articulações horizontal e vertical, preconizadas pela PNRH do Brasil. Frente a essas constatações, entende-se que, por constituir oportunidade adicional de engajamento e envolvimento público, uma abordagem participativa de AAE, que empregasse procedimentos de consulta e engajamento público de forma antecipada, seria mais apropriada para o contexto brasileiro de elaboração de PBHs, funcionando, inclusive, como mecanismo de fortalecimento do papel deliberativo dos CBHs, ampliando a racionalidade comunicativa do processo de elaboração de PBHs.

Considerando-se que, na etapa de definição do escopo da AAE são definidos os atores que participarão da elaboração e monitoramento do Plano, bem como as formas e os momentos de participação, uma possibilidade seria a definição de um grupo de atores-chave para o acompanhamento do processo de AAE que, além dos atores do CBH (como, por exemplo, os representantes de cada uma das câmaras técnicas) envolveria outros representantes da sociedade civil e de setores intervenientes na gestão dos recursos hídricos, selecionados caso a caso, de acordo com a natureza dos conflitos predominantes na bacia hidrográfica.

Assim, por meio de métodos participativos de tomada de decisão e reuniões periódicas ao longo do processo de AAE, o referido grupo de acompanhamento desempenharia papel fundamental: (i) na identificação das demandas dos diversos setores usuários; (ii) na definição dos objetivos da AAE; (iii) na seleção dos critérios utilizados para a avaliação dos cenários de desenvolvimento propostos; (iv) na avaliação da significância dos impactos ambientais das medidas de intervenção propostas e; (v) no acompanhamento da implementação do Plano.

A cada novo processo de AAE de PBH haveria também a possibilidade de inclusão de novas informações nos Sistemas Nacional e Estaduais de Informações sobre os Recursos Hídricos, permitindo o compartilhamento de dados de inventário e de diagnóstico entre PBHs desenvolvidos na mesma área de influência. Além disso, nos encontros técnico-científicos promovidos pelos Conselhos Nacional e Estaduais de Recursos Hídricos e/ou por entidades colegiadas, como o Fórum Nacional de Comitês de Bacia Hidrográfica, poderiam ser apresentadas e difundidas as abordagens metodológicas alternativas empregadas na elaboração dos PBHs submetidos à AAE.

Nesse sentido, tendo como referência etapas previstas para a elaboração de PBHs no Brasil (Brasil, 2012; Agência Nacional das Águas, 2013), o Quadro 4 sintetiza as potenciais contribuições de uma AAE sistemática e participativa para os PBHs do Brasil, identificadas a partir das boas práticas do sistema francês e dos mecanismos sugeridos na literatura para a superação das limitações identificadas nas AAEs de SAGEs.

Quadro 4. Potenciais contribuições de uma AAE sistemática e participativa para os PBHs do Brasil

\begin{tabular}{|c|c|}
\hline $\begin{array}{c}\text { Etapas previstas para a elaboração de PBHs no } \\
\text { Brasil }\end{array}$ & Etapas sequenciais básicas de processo de $\mathrm{AAE}$ \\
\hline $\begin{array}{l}\text { Diagnóstico da situação atual } \\
\text { - caracterização da bacia hidrográfica considerando } \\
\text { aspectos físicos, bióticos, socioeconômicos, políticos } \\
\text { e culturais. } \\
\text { - avaliação do quadro atual dos usos da água e das } \\
\text { demandas hídricas associadas. } \\
\text { - identificação de políticas, planos, programas e } \\
\text { projetos setoriais que interfiram nos recursos } \\
\text { hídricos. }\end{array}$ & $\begin{array}{l}\text { Linha de base ambiental } \\
\text { - Ponderação de informações relacionadas à } \\
\text { capacidade suporte do meio ambiente. } \\
\text { - Definição de objetivos e seleção de indicadores de } \\
\text { sustentabilidade ambiental de forma participativa e } \\
\text { consensual. } \\
\text { - Análise de consistência - compatibilização e } \\
\text { articulação entre os objetivos do PBH e os objetivos }\end{array}$ \\
\hline
\end{tabular}




\begin{tabular}{|c|c|}
\hline $\begin{array}{c}\text { Etapas previstas para a elaboração de PBHs no } \\
\text { Brasil }\end{array}$ & Etapas sequenciais básicas de processo de AAE \\
\hline $\begin{array}{l}\text { - caracterização de atores relevantes para a gestão } \\
\text { dos recursos hídricos e dos conflitos identificados. }\end{array}$ & $\begin{array}{l}\text { de outras políticas, planos, programas e projetos } \\
\text { setoriais que interfiram nos recursos hídricos. } \\
\text { - Envolvimento de atores-chave selecionados caso a } \\
\text { caso, além dos participantes do CBH (grupo de } \\
\text { acompanhamento). } \\
\text { - Geração de dados e informações ambientais } \\
\text { adicionais que podem integrar o Sistema Nacional de } \\
\text { Informações sobre os Recursos Hídricos. }\end{array}$ \\
\hline $\begin{array}{l}\text { Prognóstico } \\
\text { • avaliação das demandas e disponibilidades hídricas } \\
\text { dos cenários formulados. } \\
\text { • avaliação das condições da qualidade da água nos } \\
\text { cenários formulados com identificação de conflitos } \\
\text { potenciais. } \\
\text { • definição de alternativas de prevenção, ou } \\
\text { mitigação das situações críticas identificadas. } \\
\text { • definição do cenário de referência para o qual o } \\
\text { PBH orientará suas ações. }\end{array}$ & $\begin{array}{l}\text { Avaliação de impacto e questões-chave } \\
\text { - Oportunidade adicional de envolvimento da } \\
\text { sociedade civil na construção participativa de } \\
\text { cenários facilitando a articulação e a cooperação } \\
\text { institucional. } \\
\text { - Alternativas realistas e alinhadas aos anseios dos } \\
\text { diversos atores, incluindo a população afetada, } \\
\text { favorecendo o comprometimento das instituições } \\
\text { com as ações e medidas definidas. } \\
\text { - Ajuste das alternativas de desenvolvimento no } \\
\text { sentido da maximização dos efeitos ambientais } \\
\text { positivos e mitigação dos negativos. } \\
\text { - Estabelecimento de parcerias setoriais inovadoras } \\
\text { para a gestão integrada dos recursos hídricos. }\end{array}$ \\
\hline $\begin{array}{l}\text { Plano de ações } \\
\text { - definição das metas e das ações necessárias para a } \\
\text { implementação do PBH. } \\
\text { • indicadores que permitam avaliar o nível de } \\
\text { implementação das ações propostas. } \\
\text { • prioridades e cronograma de investimentos. } \\
\text { - diretrizes para os instrumentos de gestão. } \\
\text { • arranjo institucional ou recomendações de ordem } \\
\text { institucional para aperfeiçoamento da gestão dos } \\
\text { recursos hídricos e para implementação das ações } \\
\text { requeridas. }\end{array}$ & $\begin{array}{l}\text { Avaliação da significância dos impactos previstos } \\
\text { - Definição de metas e indicadores de desempenho } \\
\text { específicos, definidos com base nas demandas e } \\
\text { conflitos ambientais da bacia hidrográfica. } \\
\text { - Seleção das melhores alternativas para } \\
\text { atendimento dos usos múltiplos, considerando } \\
\text { perspectiva da sustentabilidade ambiental. } \\
\text { - Priorização de ações considerando-se o grau de } \\
\text { atendimento às demandas ambientais na bacia } \\
\text { hidrográfica. } \\
\text { - Possibilidade de proposição de programas e ações } \\
\text { emergenciais relacionados à compensação da } \\
\text { sobrecarga das alternativas de desenvolvimento na } \\
\text { base de recursos naturais. } \\
\text { - Proposição de arranjos institucionais e } \\
\text { instrumentos de gestão alternativos, tendo em vista } \\
\text { os entraves e oportunidades percebidos nas etapas } \\
\text { iniciais da AAE. }\end{array}$ \\
\hline $\begin{array}{l}\text { Monitoramento e Revisão } \\
\text { - Acompanhamento das medidas e ações propostas } \\
\text { segundo os indicadores selecionados. } \\
\text { • Elaboração de Relatórios de Acompanhamento. } \\
\text { - Revisão dos PBH. } \\
\text { - Avaliação do alcance dos objetivos e metas } \\
\text { definidos. }\end{array}$ & $\begin{array}{l}\text { Recomendações e Monitoramento } \\
\text { - Metodologia de monitoramento definidas de forma } \\
\text { participativa, baseada em indicadores de } \\
\text { sustentabilidade coerentes com a realidade da bacia } \\
\text { hidrográfica. } \\
\text { - Elaboração de Relatórios de Acompanhamento } \\
\text { facilitada pela compreensão, por parte dos diversos } \\
\text { atores, da natureza e significado dos indicadores } \\
\text { selecionados. }\end{array}$ \\
\hline
\end{tabular}

Fonte: Elaborado pelos autores (2020)

As principais vantagens da abordagem de AAE proposta decorrem da inserção sistemática da variável ambiental em todo o processo de elaboração dos PBHs e do envolvimento antecipado de atores-chave intervenientes na gestão dos recursos hídricos, incluindo representantes da população afetada. Destaca-se que, em AAE, procedimentos participativos de coleta de dados favorecem a identificação de informações adicionais e demandas futuras, ampliando os resultados do processo de avaliação em regiões com lacuna de conhecimento e/ou objetivos setoriais conflitantes (Azcarate \& Balfors, 2009). 
Dessa forma, durante a etapa de identificação da linha de base ambiental em AAE, o diagnóstico dos PBHs seria orientado por objetivos de sustentabilidade e de qualidade ambiental do sistema hídrico, ponderando, além dos parâmetros de qualidade da água, outros indicadores ambientais relacionados à capacidade suporte do meio ambiente, específicos para a bacia hidrográfica. Esses indicadores exerceriam influência em todo o processo de AAE e, também, no conteúdo do PBH, contribuindo para a avaliação das medidas propostas com base em critérios de sustentabilidade, bem como para a priorização de ações considerando-se o grau de atendimento às demandas ambientais na bacia hidrográfica.

Ademais, as discussões realizadas no âmbito do grupo de acompanhamento instituído aproximariam os atores e instituições mobilizados no âmbito do CBH da população potencialmente afetada pelo PBH. A depender da diversidade de atores envolvidos no grupo de acompanhamento, haveria também a possibilidade de estabelecimento de parcerias e articulações fundamentais para o alcance dos objetivos dos PBH, bem como a identificação de instrumentos alternativos de gestão, passíveis de aplicação no contexto da bacia hidrográfica. Por outro lado, as dificuldades de negociação identificadas nas etapas iniciais da AAE poderiam embasar a definição de diretrizes e recomendações de ordem institucional, para aperfeiçoamento da gestão dos recursos hídricos e para implementação das ações requeridas, procedimento previsto pela Resolução CNRH No 145 de 2012 (Brasil, 2012).

Na sequência, por meio da construção participativa e consensual dos cenários alternativos de desenvolvimento e da avaliação da significância dos impactos ambientais, haveria a possibilidade de seleção das melhores alternativas (do ponto de vista do atendimento aos usos múltiplos e da sustentabilidade ambiental) para a construção do cenário de referência, bem como o ajuste das alternativas de desenvolvimento selecionadas no sentido maximização das consequências ambientais positivas e mitigação das consequências negativas.

Além disso, por visar à definição de medidas de preservação dos recursos naturais e a promoção da qualidade ambiental, em situações de consequências socioambientais inevitáveis, a AAE promoveria a proposição de programas, projetos e ações emergenciais relacionados à compensação da sobrecarga das alternativas na base de recursos naturais. Por fim, o monitoramento da implementação dos PBHs se utilizaria de indicadores e critérios definidos de forma participativa, compreendidos de forma ampla pelos diversos atores, o que facilitaria a elaboração dos Relatórios anuais acompanhamento dos recursos hídricos, instrumento adotado por alguns sistemas estaduais de gerenciamento dos recursos hídricos, tendo em vista o monitoramento da implementação dos PBHs.

\section{CONCLUSÕES}

A AAE é instrumento de planejamento com estrutura e sistemática de avaliações compatíveis com o processo de elaboração de planos regionais e de desenvolvimento setorial, pautados em princípios de sustentabilidade ambiental. Por outro lado, considerando-se que na gestão integrada dos recursos hídricos os diferentes objetivos setoriais são muitas vezes conflitantes, entende-se que a definição de objetivos de desenvolvimento compartilhados pelos diversos atores institucionais é fundamental.

No presente artigo, 12 Relatórios de AAEs aplicadas aos SAGEs na França foram submetidos à sistemática revisão da qualidade. Destes, 07 apresentaram desempenho insatisfatório na determinação da significância dos impactos ambientais. Assim, à luz da prática francesa de AAE de SAGEs, pode-se afirmar que, embora a utilização de abordagens sistemáticas de AAE contribua para a consideração de objetivos de sustentabilidade durante o processo de elaboração dos PBHs, o envolvimento público de forma consistente e antecipada é procedimento fundamental, que amplia os resultados obtidos com AAE, contribuindo para a identificação de objetivos e indicadores de consenso entre os diversos atores sociais e para a consistente avaliação da significância dos impactos ambientais previstos.

Ressalta-se ainda que, no caso de abordagens sistemáticas e participativas de AAE, há outras potencialidades relacionadas: (i) à compatibilização e articulação dos objetivos dos PBHs com os objetivos de outros planos setoriais, com destaque aos Planos Diretores Municipais; (ii) à avaliação dos cenários alternativos de desenvolvimento com base em critérios ambientais e de sustentabilidade e; (iii) ao monitoramento realizado com base em indicadores coerentes com a realidade ambiental da bacia hidrográfica.

Argumenta-se, portanto, pelo potencial da AAE de atuar como mecanismo facilitador da construção de PBH integradores, mais alinhados à dinâmica territorial e ao contexto decisório de planejamento e gestão dos recursos hídricos. Além disso, o instrumento pode constituir mecanismo 
adicional de envolvimento público, com métodos e ferramentas que ampliam a racionalidade comunicativa dos processos de elaboração de PBHs. Contudo, importante destacar que a AAE não é solução para conflitos relacionados à ingerência política de determinados atores e setores usuários no âmbito dos CBHs.

Dessa forma, entende-se que estudos futuros devam direcionar esforços para a identificação de outros procedimentos e ferramentas analíticas que possibilitem a estruturação de ampla base metodológica para AAE de PBHs do Brasil. Ao mesmo tempo, entende-se como necessário o estabelecimento de parcerias junto às Agências de Água, tendo em vista a validação das abordagens metodológicas propostas e a aproximação entre a pesquisa acadêmica e os procedimentos empregados no âmbito dos CBHs.

\section{REFERÊNCIAS}

Académie de L'eau. (2013). Sensibilisation, information et éducation des publics aux problèmes de l'eau. Guide des methodes. Recuperado em 15 de outubro de 2019, de http://www.academie- eau.org/IMG/pdf/Guide_methodes_06_03.pdf

Agência Nacional das Águas - ANA. (2008). Plano Estratégico da bacia hidrográfica dos Rios Tocantins e Araguaia. Relatório Síntese (204 p.). Brasília: ANA. Recuperado em 15 de janeiro de 2020, de https://central3.to.gov.br/arquivo/269473/

Agência Nacional das Águas - ANA. (2013). Planos de Recursos Hídricos e Enquadramento dos corpos de água. (68 p., Vol. 5 -Cadernos de Capacitação em Recursos Hídricos). Brasília: ANA.

Agência Nacional das Águas - ANA. (2017). Plano de Recursos Hídricos da Região Hidrográfica do Paraguai PRH Paraguai (119 p.). Brasília: ANA/SPR, ENGECORPS ENGENHARIA S.A. Recuperado em 15 de janeiro de 2020, de http://arquivos.ana.gov.br/portal/RH-Paraguai/processo_elaboracao/arranjo_institucional.pdf

Agra Filho, S. S., \& Ramos, T. B. (2015). Analysis of the Institutional model of water management for the implementation of SEA: comparative study between Portugal and Brazil. Revista Eletrônica de Gestão e Tecnologias Ambientais, 3(2), 109-139.

Arce, R., \& Gullón, N. (2000). The application of Strategic Environmental Assessment to sustainability assessment of infrastructure development. Environmental Impact Assessment Review, 20, 393-402.

Arts, J., Tomlinson, P., \& Voogd, H. (2011). Planning in tiers? Tiering as a way of linking SEA and EIA. In B. Sadler, J. Dusik \& T. Fischer. (Eds.), Handbook of Strategic Environmental Assessment (pp. 415-433). Washington, DC: Earthscan Publications Ltd.

Azcarate, J., \& Balfors, B. (2009). Participative SEA approach data colections and objective formulation. Journal of Environmental Assessment Policy and Management, 11(2), 189-211.

Berreta, M. S. R., Laurent, F., \& Basso, L. A. (2012). Os princípios e os fundamentos da Legislação das Águas na França. Boletim Gaúcho de Geografia, 39, 13-24.

Bohn, N., Cernesson, F., Richard, S., \& Pinheiro, A. (2008). Planos de recursos hídricos: uma análise comparativa entre o SAGE (França) e o PBH (Brasil). Revista de Gestão de àgua da América Latina, 5(1), 39-50.

Braga, B. P. F., Flecha, R., Thomas, P., Cardoso, W., \& Coelho, A. C. (2009). Integrated water resources management in a Federative Country: the case of Brazil. International Journal of Water Resources Development, 25(4), 611-628.

Bragagnolo, C., \& Geneletti, D. (2012). Addressing cumulative effects in Strategic Environmental Assessment of spatial planning. Aestimum (Firenze), 60, 39-52.

Bragagnolo, C., Geneletti, D., \& Fischer, T. B. (2012). Cumulative effects in SEA of spatial plans - evidence from Italy and England. Impact Assessment and Project Appraisal, 30(2), 100-110.

Brasil. (1997). Lei no. 9.433, de 8 de janeiro de 1997. Política Nacional dos Recursos Hídricos. Diário Oficial [da] República Federativa do Brasil, Brasília.

Brasil. Conselho Nacional de Recursos Hídricos - CNRH. (2012). Resolução CNRH No 145, de 12 de dezembro de 2012. Diário Oficial [da] República Federativa do Brasil, Brasília.

Calvo-Mendieta, I., Petit, O., \& Viven, F. (2017). Common patrimony: a concept to analyze collective natural resource management. The case of water management in France. Ecological Economics, 137, 126-132.

Campos, N., \& Sousa, R. O. (2003). Planos de bacias hidrográficas. In N. Campos \& T. Studart (Orgs.), Gestão das águas: princípios e práticas (2 $2^{\mathrm{a}}$ ed., pp. 57-68). Porto Alegre: ABRH.

Carter, J., \& Howe, J. (2006). The water framework directive and the Strategic Environmental Assessment directive: exploring the linkages. Environmental Impact Assessment Review, 26(3), 287-300. 
Chaker, A., El-Fadl, K., Chamas, L., \& Hatjian, B. (2006). A review of Strategic Environmental Assessment in 12 selected countries. Environmental Impact Assessment Review, 26(1), 15-56.

Connelly, S., \& Richardson, T. (2005). Value-driven SEA: time for an environmental justice perspective? Environmental Impact Assessment Review, 25(4), 391-409.

Dalal-Clayton, B., \& Sadler, B. (2005). Strategic Environmental Assessment: a sourcebook and reference guide to international experience (504 p.). London: Earthscan.

Dalkmann, H., Jiliberto Herrera, R., \& Bongardt, D. (2004). Analytical Strategic Environmental Assessment (ANSEA) developing a new approach to SEA. Environmental Impact Assessment Review, 24, 385-402.

Donnelly, A., Prendergast, T., \& Hanusch, M. (2008). Examining quality of environmental objectives, targets and indicators in Environmental Reports prepared for Strategic Environmental Assessment. Journal of Environmental Assessment Policy and Management, 10(4), 381-401.

Espinosa, H. R. M. (1996). Diretrizes para uma política ambiental sustentabilista. Avaliação de Impactos, 1(2), 79-87.

Fischer, T. (2003). Strategic Environmental Assessment in post-modern times. Environmental Impact Assessment Review, $23,155-170$.

Fischer, T. B. (2007). Theory and practice of Strategic Environmental Assessment: towards a more systematic approach. London, UK: Earthscan Publications Ltd.

Fischer, T. B. (2010). Reviewing the quality of Strategic Environmental Assessment reports for english spatial plan core strategies. Environmental Impact Assessment Review, 30, 62-69.

Fischer, T. B., \& Gazzola, P. (2006). SEA effectiveness criteria: equally valid in all countries? The case of Italy. Environmental Impact Assessment Review, 26(4), 396-409.

France. Ministère de l'Écologie, de l'Énergie, du Développement durable et de l’Aménagement du territoire. (2012). AcTeon: guide méthodologique pour l'élaboration et la mise en oeuvre des Schémas d'Aménagement et de Gestion des Eaux. Recuperado em 15 de abril de 2020, de http://www.gesteau.fr/sites/default/files/gesteau/content_files/document/guidesage_2015.pdf

Fry, C., McColl, V., Tomlinson, P., Eales, R., \& Smith, S. (2002). Analysis of baseline data requirements for the SEA directive final report. TRL Ltd and Collingwood Environmental Planning.

Gullón, N. (2005). Links between the water framework directive and SEA. In M. Shmidt \& E. João (Eds.), Implementing Strategic Environmental Assessment (pp. 513-521). Berlim: Springer-Verlag.

Harding, R. (1998) (Ed.). Environmental decision-making: the role of scientists, engineers and the public. Sydney, Austrália: Federation Press.

Jacobi, P. R., Cibim, J., \& Leão, R. S. (2015). Crise hídrica na Macrometrópole Paulista e respostas da sociedade civil. Estudos Avançados, 29(84), 27-42.

Jiricka, A., \& Probstl, U. (2008). SEA in local land use planning: first experience in the Alpine States. Environmental Impact Assessment Review, 28(4-5), 328-337.

Lanna, A. E., Pereira, J. S., \& Hubert, G. (2002). Os Novos Instrumentos de Planejamento do Sistema Francês de Gestão de Recursos Hídricos: II - Reflexões e Propostas para o Brasil. Revista Brasileira de Recursos Hídricos, 7(2), 109-120.

Larsen, S. V., \& Kornov, L. (2009). SEA of River Basin Management Plans: Incorporating Climate Change. Impact Assessment and Project Appraisal, 27(4), 291-299.

Le Service Public D'information sur L'eau - EUFRANCE. (2014). Service d'Administration Nationale des Données et Référentiels sur l'Eau - SANDRE. Recuperado em 15 de outubro de 2014, de https://www.gesteau.fr/sage\#5/46.740/5.515/sdage,sage

Lee, N. (2006). Bridging the gap between theory and practice in integrated assessment. Environmental Impact Assessment Review, 26, 57-78.

Lee, N., \& Colley, R. (1987). Reviewing the quality of environmental statements, occasional (Paper 24). Manchester: University of Manchester.

Lemos, C. C., Fischer, T. B., \& Souza, M. P. (2012). Strategic Environmental Assessment in tourism planning: extent of application and quality of documentation. Environmental Impact Assessment Review, 35, 1-10.

Leone, F., \& Zoppi, C. (2019). Local Development and protection of nature in coastal zones: a planning study for the Sulcis Area (Sardinia, Italy). Sustainability, 11(18), 1-21.

Liefferink, D., Wiering, M., \& Uitenboogaart, Y. (2011). The EU water framework directive: a multi-dimensional analysis of implementation and domestic impact. Land Use Policy, 28, 712-722. 
Liu, B., \& Speed, R. (2009). Water resources management in the people's Republic of China. International Journal of Water Resources Development, 25(2), 193-208.

Machado, C. J. S. (2003). A gestão francesa de recursos hídricos: descrição e análise dos princípios jurídicos. Revista Brasileira de Recursos Hídricos, 8(4), 31-47.

Malheiros, T. F., Prota, M. G., \& Perez Rincón, M. A. P. (2013). Participação comunitária e implementação dos instrumentos de gestão da água em bacias hidrográficas. Revista Ambiente \& Água, 8(1), 98-118.

Martins, R. C. (2008). Sociologia da governança francesa das águas. Revista Brasileira de Ciências Sociais, 23(67), 83-190.

McCluskey, D., \& João, E. (2011). The promotion of environmental enhancement in Strategic Environmental Assessment. Environmental Impact Assessment Review, 31, 344-351.

Milaré, E. (Ed.). (2014). Direiro do ambiente (9. ed.). São Paulo: Revista dos Tribunais.

Montaño, M., Oppermann, P., Malvestio, A. C., \& Souza, M. P. (2014). Current state of the SEA system in Brazil: a comparative study. Journal of Environmental Assessment Policy and Management, 16(2), 1450022.

Monteiro, M. B., \& Partidário, M. R. (2017). Governance in Strategic Environmental Assessment: lessons from the portuguese practice. Environmental Impact Assessment Review, 65, 125-138.

Montis, A. (2014). Strategic Environmental Assessment of energy planning tools. A study of Italian regions and provinces. Environmental Impact Assessment Review, 46, 32-42.

Noble, B., \& Nwanekezie, K. (2017). Conceptualizing Strategic Environmental Assessment: principles, approaches and research directions. Environmental Impact Assessment Review, 62, 165-173.

Organization for Economic Cooperation and Development - OECD. (2003). Organização para a Cooperação e o Desenvolvimento Econômico. Environmental indicators: development, measurement and use. Paris: OECD.

Partidário, M. R. (2007). Scales and associated data: what is enough for SEA needs? Environmental Impact Assessment Review, 27, 460-478.

Phylip-Jones, J., \& Fischer, T. B. (2015). Strategic Environmental Assessment (SEA) for wind energy planning: lessons from the United Kingdom and Germany. Environmental Impact Assessment Review, 50, 2013-2012.

Pizella, D. G. (2019). Avaliação Ambiental Estratégica como instrumento para a Gestão Integrada dos Recursos Hídricos: Estudo de caso do Plano de Bacia do São José dos Dourados e do Plano Diretor Municipal de Ilha Solteira, SP. Holos Environment, 19(3), 338-355.

Pizella, D. G., \& Souza, M. P. (2013). Strategic Environmental Assessment for watershed management plans. Engenharia Sanitaria e Ambiental, 18(3), 243-252.

Polido, A., \& Ramos, T. B. (2015). Towards effective scoping in Strategic Environmental Assessment. Impact Assessment and Project Appraisal, 33(3), 171-183.

Polido, A., João, E., \& Ramos, T. B. (2016). Exploring experts' views and perspectives on the enhancement of Strategic Environmental Assessment in European small islands. Environmental Impact Assessment Review, 58, 25-33.

Porto, M. F. A., \& Porto, R. L. L. (2008). Gestão de bacias hidrográficas. Estudos Avançados, 22(63), 43-60.

Sánchez, L. E. (2006). Avaliação de Impacto Ambiental: conceitos e métodos. São Paulo: Ed. Oficina de Textos.

Santos, S. M., Souza, M. M. P., Bircol, G. A. C., \& Ueno, H. M. (2020). Planos de Bacia e seus desafios: o caso da Bacia Hidrográfica do Alto Tietê - SP. Ambiente e Sociedade, 23, e02342.

Sinclair, A. J., Sims, L., \& Spaling, H. (2009). Community-based approaches to Strategic Environmental Assessment: lessons from Costa Rica. Environmental Impact Assessment Review, 29, 147-156.

Singleton, R., Castle, P., \& Short, D. (1999). Environmental assessment. London, UK: Thomas Telford Publishing.

Stookes, P. (2003). Getting to the real EIA. Journal of Environmental Law, 15(2), 141-151.

Tetlow, M. F., \& Hanush, M. (2012). Strategic Environmental Assessment: the state of the art. Impact Assessment and Project Appraisal, 30(1), 15-24.

Therivel, R. (2004). Strategic Environmental Assessment in action. London, UK: Earthscan Publications Ltd.

Tucci, C. (2006) Água no meio Urbano. In A. C. Rebouças (Org.), Águas doces do Brasil (3. ed., pp. 399-432). São Paulo: Escrituras.

Vammen, S. (2008, May 4-10). SEA of River basin management plans: incorporating climate change. In IAIA08 Conference Proceedings. Perth, Austrália. 
Vasconcelos, M. (2013). Avaliação ambiental estratégica para a gestão integrada e participativa dos recursos hídricos. In W. S. Lira \& G. A. Cândido (Orgs.), Gestão sustentável dos recursos naturais: uma abordagem participativa (pp. 295318). Campina Grande: EDUEPB. Recuperado em 15 de janeiro de 2020, de http://books.scielo.org/id/bxj5n/pdf/lira-9788578792824-13.pdf

Veiga, L. B., \& Magrini, A. (2013). The Brazilian water resources management policy: fifteen years of success and challenges. Water Resources Management, 27(7), 2287-2302.

Vicente, F., \& Méndez, G. (2015). Strategic environment assessment of river basin management plans: proposal for an integrated assessment. Journal of Environmental Assessment Policy \& Management, 17(3), 15500.

Wood, C. (2000). Screening and scoping. In N. Lee \& C. George (Orgs.), Environmental Assessment in developing and transitional countries (pp. 71- 84). Chichester: John Wiley \& Sons.

Zuffo, A. C., \& Zuffo, M. S. R. (2016). Gerenciamento de Recursos Hídricos: Conceituação e Contextualização (480 p.) São Paulo: Elsevier.

\section{Contribuição do autores:}

Simone Mendonça dos Santos - Contribuição: Definição do objetivo, escopo e metodologia da pesquisa; coleta e análise dos dados; discussões e elaboração do manuscrito.

Denise Gallo Pizella - Contribuição: Análise dos dados; discussões e elaboração do manuscrito.

Marcelo Marini Pereira de Souza - Contribuições: Orientação da pesquisa; análise dos dados; discussões e elaboração do manuscrito. 